\title{
Un cuarto de siglo de investigación genética en los trastornos neuropsiquiátricos en Costa Rica
}

\author{
Patricia Bolaños-Palmieri ${ }^{1,2+}$, Gabriela Chavarria-Soley ${ }^{1,2 *+}$, Javier Contreras ${ }^{2}$ \\ \& Henriette Raventós ${ }^{1,2}$ \\ 1. Escuela de Biología, Universidad de Costa Rica; pbolanosp@gmail.com, gabriela.chavarriasoley@ucr.ac.cr, \\ henriette.raventos@ucr.ac.cr \\ 2. Centro de Investigación en Biología Celular y Molecular, Universidad de Costa Rica; luis.contreras@ucr.ac.cr \\ * Correspondencia \\ + ambas autoras contribuyeron en igual medida a la elaboración de este trabajo
}

Recibido 04-X-2017. C Corregido 24-I-2019. Aceptado 06-II-2019.

\begin{abstract}
A quarter century of genetic research on neuropsychiatric disorders in Costa Rica. In Costa Rica, the study of the genetic basis of neuropsychiatric disorders started more than 25 years ago. During this time, different research efforts have focused on several disorders: schizophrenia, bipolar disorder, Alzheimer's disease, obsessive-compulsive disorder, attention deficit/hyperactivity disorder, and Tourette syndrome. The studies have had a wide scope regarding design (linkage/association), sample used (families/sib pairs/trios), genome coverage (candidate gene studies/genome-wide scans), and phenotype definition (diagnostic category/ syndromic classification/endophenotype). Here we present a summary of the main genomic findings of these multidisciplinary studies, and discuss the importance, lessons, and challenges of genetic research of complex psychiatric disorders.
\end{abstract}

Key words: psychiatry; brain; gene mapping; phenotype; endophenotype; gene.

Bolaños-Palmieri, P., Chavarria-Soley, G., Contreras, J. \& Raventós, H. (2019). Un cuarto de siglo de investigación genética en los trastornos neuropsiquiátricos en Costa Rica. Revista de Biología Tropical, 67(2) Suplemento, S1-S25.

Desde hace más de un cuarto de siglo, se han estudiado alrededor de 6000 individuos de la población de Costa Rica para identificar loci y variantes genéticas asociadas al riesgo de padecer diferentes trastornos neuropsiquiátricos. Costa Rica como país presenta varias ventajas para realizar estudios en enfermedades genéticas: existencia de familias grandes ideales para estudios clásicos de ligamiento, excelentes registros médicos y genealógicos (algunos desde la época de la colonia) y una población con nivel de escolaridad relativamente alto y colaboradora con la investigación biomédica.

Con frecuencia se ha defendido que el Valle Central es un buen sitio para estudios genéticos por constituir un aislado poblacional (Mathews et al., 2004). Sin embargo, algunos estudios que se han enfocado en medir niveles de consanguinidad y analizar marcadores moleculares en la población han llegado a la conclusión de que el Valle Central no cumple los requisitos para ser considerado un aislado poblacional (Morera, Barrantes, \& Marin-Rojas, 2003; Morera \& Barrantes, 2004; Segura-Wang, Raventós, Escamilla, \& Barrantes, 2010). Se ha encontrado que, al igual que en muchas poblaciones latinoamericanas, la composición genética de la población costarricense presenta contribución de genes de origen europeo, amerindio y africano, en ese orden 
de frecuencia (Morera et al., 2003; Morera \& Barrantes, 2004). Es importante tener en cuenta la estructura genética de la población a la hora de interpretar los resultados de estudios en los que se investigan rasgos genéticos.

Las estrategias de mapeo en Costa Rica han consistido principalmente en estudios de ligamiento y de asociación para identificar regiones genómicas candidatas, y como siguiente paso identificar genes y variantes alélicas que aumenten el riesgo de presentar algún trastorno psiquiátrico. Más recientemente, se han incorporado nuevas estrategias para el estudio de los trastornos mentales en el país, como por ejemplo la identificación de endofenotipos y el estudio de su base genética, en lugar de utilizar categorías diagnósticas. Finalmente, en años recientes, con el abaratamiento de las técnicas de secuenciación y después del éxito modesto de los estudios poblacionales de asociación- lo que se ha descrito como la heredabilidad faltante- nuestros abordajes han dado un giro hacia estudiar de nuevo familias con alta densidad de personas afectadas.

En el presente artículo presentamos una revisión de los principales resultados genómicos que se han obtenido para los trastornos psiquiátricos estudiados en Costa Rica, iniciando con una sección acerca de la definición del fenotipo en psiquiatría, siguiendo con la presentación del concepto de endofenotipo, y posteriormente, resumiendo los resultados encontrados en esquizofrenia, trastorno bipolar, demencia de Alzheimer, trastorno obsesivo compulsivo, trastorno por déficit de atención y síndrome de Tourette. Aunque se han realizado análisis funcionales para algunas variantes genéticas de riesgo identificadas en el país, esta revisión se enfoca en los resultados de los estudios de epidemiología genética.

\section{La definición del fenotipo en los trastornos psiquiátricos para estudios genéticos}

La definición del fenotipo en psiquiatría genética constituye una limitante importante en la mayoría de las investigaciones. Las características fenotípicas se evalúan con escalas subjetivas y los diagnósticos se basan en un reporte de síntomas, los cuales no están presentes en todos los individuos que tienen un mismo diagnóstico. Algunos trastornos psiquiátricos con psicosis como la esquizofrenia, el trastorno esquizoafectivo y el trastorno bipolar con psicosis, se traslapan en muchas dimensiones, incluyendo síntomatología, neurocognición y tratamiento. Familias con individuos con esquizofrenia, muchas veces tienen otros individuos con trastorno bipolar y esquizoafectivo. Un estudio de la caracterización clínica de una muestra en Costa Rica mostró que más de la mitad de los pacientes con esquizofrenia tienen síntomas afectivos, particularmente síntomas depresivos (Contreras et al., 2009). Otro reporte de la misma población evidenció que el $97.6 \%$ de los individuos con trastorno bipolar reportan una historia de psicosis, lo que podría explicar las similitudes clínicas encontradas entre ellos y personas con esquizofrenia (Pacheco et al., 2010).

Las clasificaciones diagnósticas internacionales como la Clasificación Internacional de Enfermedades, décima versión (CIE-10) de la Organización Mundial de la Salud y el Manual Diagnóstico y Estadístico de los Trastornos Mentales (DSM) de la Asociación Americana de Psiquiatría han permitido la unificación de criterios diagnósticos. Dichas clasificaciones son necesarias tanto en la práctica clínica para establecer un diagnóstico inicial presuntivo, escoger el tratamiento y pronóstico, como para garantizar el disfrute de derechos laborales y de cobertura de seguros en los pacientes (Raventós \& Contreras, 2017). Además, en la investigación genética estas clasificaciones juegan un papel clave porque permiten establecer los criterios de inclusión o exclusión. Sin embargo, no son suficientes. Además de contar con el referente diagnóstico para establecer el fenotipo según estos criterios clínicos, se requiere un proceso sistematizado que permita recopilar la mayor cantidad de información clínica para cada sujeto de estudio. Usualmente se utiliza el proceso de mejor estimado diagnóstico (MED), que se considera el estándar de oro en la definición del fenotipo en trastornos psiquiátricos 
(Contreras et al., 2009). En este proceso, la información clínica se recolecta de tres fuentes: la Entrevista Diagnóstica para Estudios Genéticos (Diagnostic Interview for Genetic Studies, DIGS) (Nurnberger et al., 1994), la Entrevista Familiar para Estudios Genéticos (Family Interview for Genetic Studies, FIGS) (Maxwell, 1992) y la revisión de los registros médicos. El clínico que completa el DIGS es ciego a la historia familiar, los registros médicos o cualquier otra información que no se derive de la entrevista directa. Además de esta fuente de información directa, es necesario contar con información adicional de la familia (FIGS) y los expedientes médicos para alcanzar un diagnóstico certero, principalmente en trastornos afectivos y en trastornos psicóticos. El diagnóstico final o MED se obtiene a través de un proceso donde dos psiquiatras independientes revisan la información disponible de estas tres fuentes, proponen un diagnóstico, y posteriormente, mediante la discusión conjunta, alcanzan un diagnóstico de consenso.

\section{La utilidad del concepto de endofenotipo en trastornos psiquiátricos}

Un endofenotipo se define como un rasgo cuantificable que no se puede observar a simple vista y que se ubica más próximo a la base genética de una enfermedad que el fenotipo clínico (Gottesman \& Gould, 2003). Para que una característica sea considerada como un endofenotipo debe cumplir los siguientes criterios: (a) Asociación con la enfermedad en la población, (b) Que sea heredable, (c) Correlación genética con el fenotipo en estudio, (d) Estado-independiente (no asociado a episodio agudo de la enfermedad), (e) Mayor prevalencia en los familiares enfermos que en familiares sanos de un probando con la enfermedad (dentro de las familias, endofenotipo y enfermedad co-segregan) y (f) Mayor prevalencia en familiares no afectados que en la población general (Gottesman \& Gould, 2003).

Estos fenotipos cuantitativos o endofenotipos han ganado popularidad en los últimos años. Se asume que su enfoque cuantitativo permite una mayor aproximación etiológica al espectro clínico del trastorno. En trastornos psiquiátricos, el estudio de endofenotipos tiene la ventaja de que éstos se pueden cuantificar mediante métodos menos complejos que los actuales constructos diagnósticos (Glahn et al., 2014). Nuestro grupo ha determinado que la ansiedad de rasgo (pero no la de estado) cumple los criterios para ser considerada como un endofenotipo para trastorno bipolar (Contreras, Hare, Pacheco, Escamilla, \& Raventos, 2010; Contreras, Hare, Chavarría, \& Raventós, 2018). Con una muestra de 619 individuos costarricenses, se llevó a cabo un análisis de ligamiento de rasgo cuantitativo (QTL) para la ansiedad de rasgo. Se identificó una señal sugerente de ligamiento en la región 2q13-q14 (Contreras, Hare, Chavarría-Soley, \& Raventós, 2018). Además, se han identificado algunas variables neurocognitivas como endofenotipos candidatos, también para trastorno bipolar (Glahn et al., 2010).

\section{Esquizofrenia}

La esquizofrenia es un trastorno psiquiátrico crónico que afecta aproximadamente al $1 \%$ de la población mundial y representa uno de los contribuyentes principales al deterioro de la salud mental (Vos et al., 2012). Tradicionalmente, las manifestaciones clínicas se han dividido en positivas y negativas. Las primeras se caracterizan por una exageración de funciones normales y la presencia de algo que debería estar ausente: pérdida de contacto con la realidad, alucinaciones, ilusiones, comportamiento y pensamientos desorganizados. Las negativas están caracterizadas por la ausencia de lo que debería estar presente: la avolición, reducido sentimiento de placer y disminución en el habla (Andreasen, 1995). Las manifestaciones clínicas pueden relacionarse con perturbaciones en las relaciones sociales, familiares y laborales de las personas con dicha enfermedad. En los países centroamericanos, la esquizofrenia es la segunda causa de hospitalizaciones en instituciones psiquiátricas (PAHOWHO, 2013). Este trastorno tiene una etiología 
compleja (Insel, 2010) y se asocia con un alto costo personal y social, que resulta en una alta discapacidad funcional (Perkins et al., 2007; Beveridge et al., 2008).

La genética juega un papel importante en el riesgo de desarrollar esquizofrenia. Algunos estudios han encontrado que entre el $65 \mathrm{y}$ el $80 \%$ de la varianza fenotípica puede ser atribuida a factores genéticos (Iyegbe, Campbell, Butler, Ajnakina, \& Sham, 2014; Sullivan, Kendler, \& Neale, 2003). A pesar de esto, la identificación de los genes involucrados en la etiopatogenia ha sido difícil. Esto muy probablemente se debe al alto número de loci y alelos que están involucrados en la arquitectura genética de la enfermedad (Mowry \& Gratten, 2013; Schizophrenia Working Group of the Psychiatric Genomics Consortium, 2014; Giegling et al., 2017), así como a la fuerte influencia de factores ambientales en el desarrollo del trastorno y el papel de alteraciones epigenéticas (Beveridge et al., 2008). Actualmente se considera que el componente genético de la esquizofrenia está compuesto de una combinación de variantes comunes y raras, que junto con variación estructural genómica modifican el riesgo de estar afectado con este trastorno (McClellan, Susser, \& King, 2007; Sebat, Levy, \& McCarthy, 2009; Schizophrenia Working Group of the Psychiatric Genomics Consortium, 2014; Giegling et al., 2017).

Los estudios de ligamiento o asociación basados en tamizaje de todo el genoma que se han hecho en Costa Rica han dado resultados similares a los obtenidos en otras partes del mundo. Se han detectado múltiples regiones candidatas a lo largo del genoma, muchas de ellas no replicadas. Específicamente en los estudios de ligamiento, se encontraron regiones cromosómicas grandes, que típicamente incluyen varios genes que podrían estar involucrados en el desarrollo de la enfermedad. En el cuadro 1 se presentan resultados detallados para estos estudios realizados con población costarricense.

Un metaanálisis que fue llevado a cabo por Ng y colaboradores (2009), que incluyó 32 estudios de ligamiento independientes de todo el mundo (dos de los cuales eran de Costa Rica), identificó una significancia sugerente a nivel de todo el genoma en el brazo largo de los cromosomas 2 y 5 . Esto concuerda con los resultados obtenidos por estudios previos (DeLisi et al., 2002; Escamilla et al., 2007) para la muestra costarricense (Cuadro 1). Un estudio de asociación de todo el genoma para esquizofrenia que incluyó aproximadamente 37000 casos y 113000 controles e identificó 108 loci asociados con la enfermedad (Schizophrenia Working Group of the Psychiatric Genomics Consortium, 2014) también identificó la región candidata 2q22.3 de la muestra costarricense. Por otro lado, la región 5q31-35 es una candidata interesante para genes involucrados en trastornos psiquiátricos, ya que ha sido encontrada en varios estudios. Ha sido identificada en un estudio de esquizofrenia y psicosis en una población portuguesa (Sklar et al., 2004), una muestra finlandesa (Paunio et al., 2001), muestras británicas e islandesas (Gurling et al., 2001), tres cohortes con ancestría europea (Gladwin et al., 2012) y en el estudio que identificó 108 loci asociados con la enfermedad (Schizophrenia Working Group of the Psychiatric Genomics Consortium, 2014). En este último estudio, únicamente una decena de genes presentaron SNPs asociados con esquizofrenia que son codificantes y resultan en el cambio de un aminoácido; uno de estos genes es PCDHA1, ubicado en 5q31. Además, esta región ha sido identificada como candidata para trastorno bipolar en dos estudios costarricenses (Herzberg et al., 2006; Jasinska et al., 2009).

En el metaanálisis de $\mathrm{Ng}$ y colaboradores previamente mencionado (2009) también se identificó evidencia sugerente de ligamiento para esquizofrenia en el cromosoma $8 \mathrm{p}$, al analizar $69 \%$ de las muestras que eran de origen europeo. Esta misma región genómica mostró una señal positiva en las muestras de Costa Rica para esquizofrenia y trastorno bipolar severo (Ophoff et al., 2002; Walss-Bass, Montero, et al., 2006), y ha sido replicada consistentemente en otros estudios (Gurling et al., 2001; Fallin et al., 2011; Holliday, Mowry, 


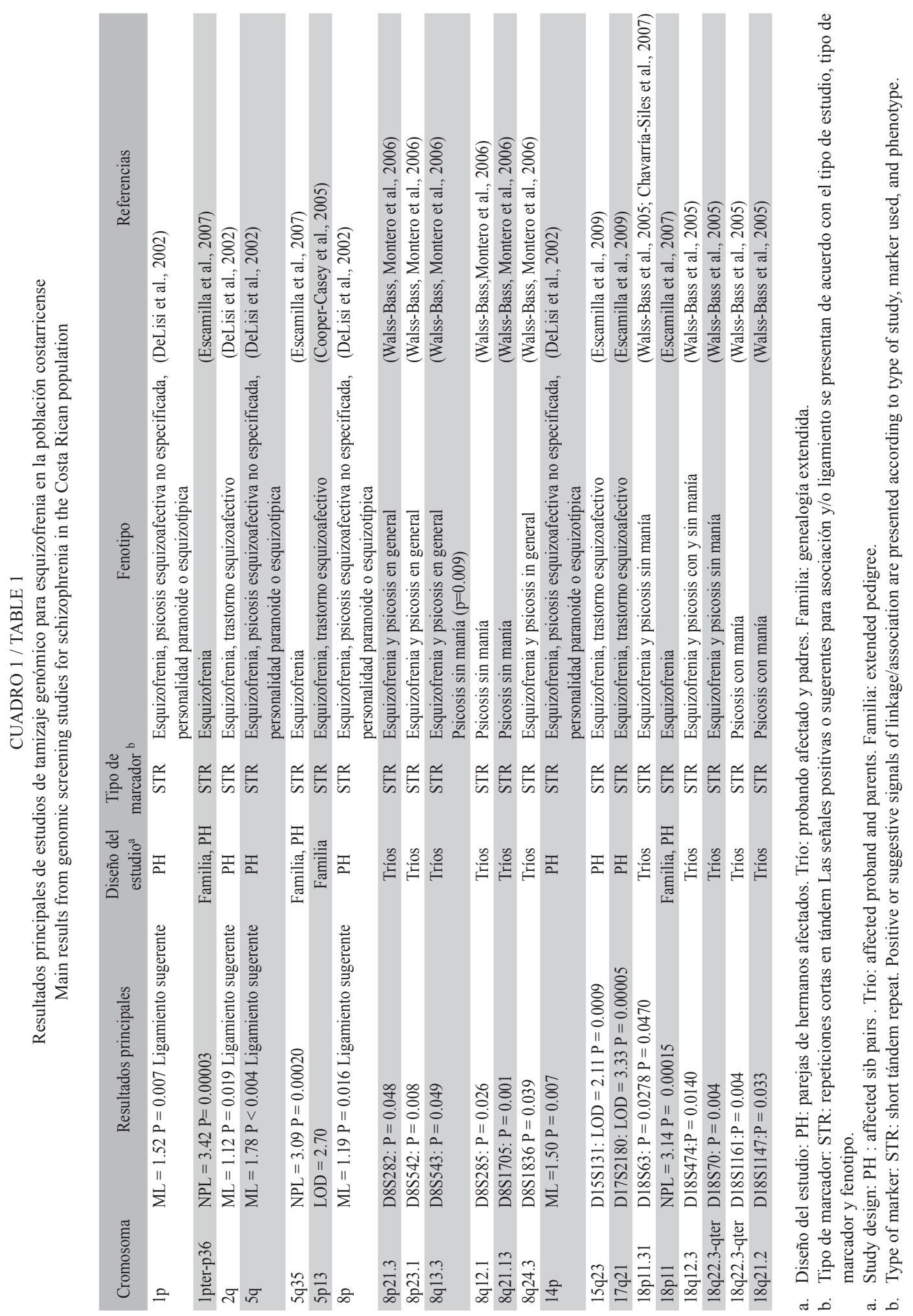


\& Nyholt, 2008; Schizophrenia Psychiatric Genome-Wide Association Consortium, 2011; Schizophrenia Working Group of the Psychiatric Genomics Consortium, 2014).

Los resultados del estudio del Schizophrenia Psychiatric Genome Wide Association Consortium (2011) identificaron una señal positiva de asociación en brazo corto del cromosoma 1 que replica los resultados obtenidos por DeLisi y colaboradores (2002) y Escamilla y colaboradores (2007) para la población costarricense, así como para una población afrikáner fundadora en Suráfrica (Abecasis et al., 2004). Este mismo consorcio también identificó en esta región, 1p21.3, una variante (rs1625579) en un intrón del microARN miR-137 con una fuerte señal de asociación con esquizofrenia. La región en que se ubica este microARN fue uno de los 108 loci asociados con la esquizofrenia identificados por el Schizophrenia Working Group of the Psychiatric Genomics Consortium (2014).

La asociación del SNP rs1625579 en miR137 no fue replicada por el grupo de psiquiatría genética del Centro de Investigación en Biología Celular y Molecular en una muestra de 52 tríos costarricenses con al menos una persona con psicosis $\left(\mathrm{X}^{2}=1, \mathrm{P}=0.32\right.$; Haploview v4.2 para la prueba TDT). La frecuencia del alelo menor (que corresponde al alelo C) fue 0.08 en la muestra costarricense (datos no publicados). Por otro lado, para los individuos de esta muestra se identificó el genotipo para una repetición en tándem de número variable (VNTR) previamente reportada, que está ubicada en la región corriente arriba de miR-137 (Bemis et al., 2008). Estudios previos han encontrado que el tamaño de la repetición puede influir sobre la expresión del gen (Mamdani et al., 2013; Warburton, Breen, Rujescu, Bubb, \& Quinn, 2015). En la población costarricense se detectaron únicamente dos alelos, con 3 y 4 repeticiones. La frecuencia del alelo menor de 4 repeticiones fue 0.19 . No se detectó asociación (usando la prueba TDT) entre ninguno de los alelos y esquizofrenia $\left(\mathrm{X}^{2}=0.05, \mathrm{P}=0.83\right)$. Sin embargo, encontramos una menor edad de inicio en los individuos afectados con al menos un alelo de 4 repeticiones, al ser comparados con los individuos homocigotos para el alelo $3(\mathrm{t}=$ $2,3$, g.1. $=44, \mathrm{P}=0,026)$. Después de aumentar la muestra a 132 individuos afectados, no fue posible replicar este resultado y no se observaron diferencias significativas en edad de inicio entre genotipos (Ávila, 2018).

Otra región genómica de interés fue identificada por primera vez en un análisis de ligamiento para esquizofrenia y está en el brazo largo del cromosoma 17 (Lewis et al., 2003). Otros estudios han aportado evidencia a favor de esta señal positiva, como por ejemplo un análisis de ligamiento usando marcadores STR en Costa Rica (Escamilla et al., 2009), así como análisis de variantes en el número de copias (CNVs) en poblaciones europeas (Moreno-DeLuca et al., 2010; Buizer-Voskamp et al., 2011).

Por último, ha existido una relación consistente entre el cromosoma 18 y trastornos psiquiátricos en la población costarricense. Para esquizofrenia, la señal de ligamiento inicial en el brazo corto de ese cromosoma fue reportada por (Walss-Bass et al., 2005) y posteriormente replicada en una muestra independiente de Costa Rica por (Chavarría-Siles et al., 2007). La misma región había sido previamente encontrada en pacientes con una forma severa de trastorno bipolar tipo I (McInnes et al., 2001). La otra señal positiva con marcadores localizados en el brazo lago del cromosoma 18 (18q21.2) (Walss-Bass et al., 2005) también ha sido replicada en otros estudios para esquizofrenia (Schizophrenia Psychiatric Genome-Wide Association Consortium, 2011), así como en pacientes con trastorno bipolar tipo I (Sklar et al., 2008).

Es importante resaltar que muchas de las regiones genómicas con señales positivas de ligamiento o asociación con esquizofrenia en la población costarricense $(8 \mathrm{p} 21,8 \mathrm{p} 23,8 \mathrm{q} 24$, $18 \mathrm{p} 11,18 \mathrm{q} 22)$ tienen al menos un reporte de anomalías cromosómicas que cosegregan con enfermedad mental, en particular los diagnósticos que incluyen síntomas psicóticos y afectivos (MacIntyre, Blackwood, Porteous, Pickard, \& Muir, 2003). La existencia de evidencia de fuentes diversas, con diferentes metodologías 
$\mathrm{y}$ en varias poblaciones fortalece los hallazgos genómicos en la población costarricense. El análisis de genes candidatos dentro de las regiones genómicas identificadas en estudios de ligamiento y asociación ha representado una fuente adicional de información. En el cuadro 2 se presenta un resumen del análisis de genes candidatos en la población costarricense.

\section{Trastorno bipolar}

El trastorno bipolar es un síndrome debilitante que se caracteriza por un grupo heterogéneo de síntomas y signos, que incluyen episodios de manía y depresión. Esta forma severa de enfermedad mental está comúnmente asociada con altas tasas de comorbilidad-por ejemplo con abuso de alcohol y ansiedad(Contreras, Hare, Escamilla, \& Raventos, 2012; Carmiol et al., 2014) y mortalidaddebido al riesgo de suicidio- (Hawton, Sutton, Haw, Sinclair, \& Harriss, 2005). Su prevalencia oscila entre el 1 y el $5 \%$ de la población, sin embargo este estimado varía de acuerdo con el diseño del estudio y la definición de diagnóstico usada dentro del espectro bipolar (Bauer \& Pfennig, 2005). Tal como en el resto de las enfermedades mentales en general, ser diagnosticado con trastorno bipolar conlleva un alto costo personal y social. Por ejemplo, en una muestra tomada del Valle Central de Costa Rica se encontró que alrededor del $40 \%$ de las personas que presentan trastorno bipolar tipo I y el $70 \%$ de las personas con esquizofrenia están desempleadas, lo cual representa una proporción mucho más alta que la tasa de desempleo por debajo del $7 \%$ de la población general (Pacheco et al., 2010).

Tal como en la esquizofrenia, la etiología del trastorno bipolar es de naturaleza compleja y no completamente comprendida. Sin embargo, existe evidencia fuerte que sugiere que una arquitectura genética heterogénea contribuye significativamente a la predisposición a esta enfermedad (Smoller \& Finn, 2003; Barnett \& Smoller, 2009; Craddock \& Sklar, 2013), con algunos estimados de heredabilidad que oscilan desde un $62 \%$ en una muestra de la población danesa (Wray \& Gottesman, 2012) hasta más de un $85 \%$ que se ha reportado en estudios de gemelos (McGuffin et al., 2003). $\mathrm{Al}$ igual que en la mayoría de las enfermedades complejas, el estudio del componente genético del trastorno bipolar ha resultado ser una tarea altamente retadora.

Desde 1996 varios grupos de investigación han considerado a la población costarricense como una muestra adecuada para la investigación en psiquiatría (Escamilla et al., 1996; Freimer, Reus, Escamilla, Spesny et al., 1996). Se han encontrado varios resultados importantes en los estudios del trastorno bipolar en Costa Rica, con evidencia de asociación o ligamiento en los cromosomas 5 y 18 (Cuadro 3). En un metaanálisis de 18 juegos de datos de tamizajes genómicos para enfermedad bipolar, y que utilizó tres modelos distintos del fenotipo para el análisis, únicamente se encontró evidencia de ligamiento estadísticamente significativa (pero que no mantiene la significancia después de corrección para pruebas múltiples) para algunas regiones del genoma (Segurado et al., 2003). Entre estas regiones se encontraron algunas de las identificadas para la muestra costarricense (Cuadro 3), como la del cromosoma 14q24.1-32.12, la de 8q24 y la de 11p13. Además, la región $18 \mathrm{q} 22$ obtuvo un puntaje sugerente de ligamiento en un estudio con 972 familias con trastorno bipolar (Badner et al., 2012). La señal de la región 5q31-33 identificada en la población costarricense se ha encontrado también en otros estudios de ligamiento (Mirow et al., 1994; Shink et al., 2002; Park et al., 2004). Por otro lado, las regiones $2 \mathrm{q} 14$ y 8 p23 identificadas en población costarricense fueron también identificadas como regiones de interés en estudio de asociación de todo el genoma con individuos de Canadá e Inglaterra (Xu et al., 2014).

Es importante hacer notar que las señales fuertes dentro de las regiones cromosómicas identificadas para el trastorno bipolar tipo I también han sido descritas para la muestra costarricense con esquizofrenia que se ha estudiado (Cuadro 1). Esto sugiere un posible traslape en genes de susceptibilidad entre estos 

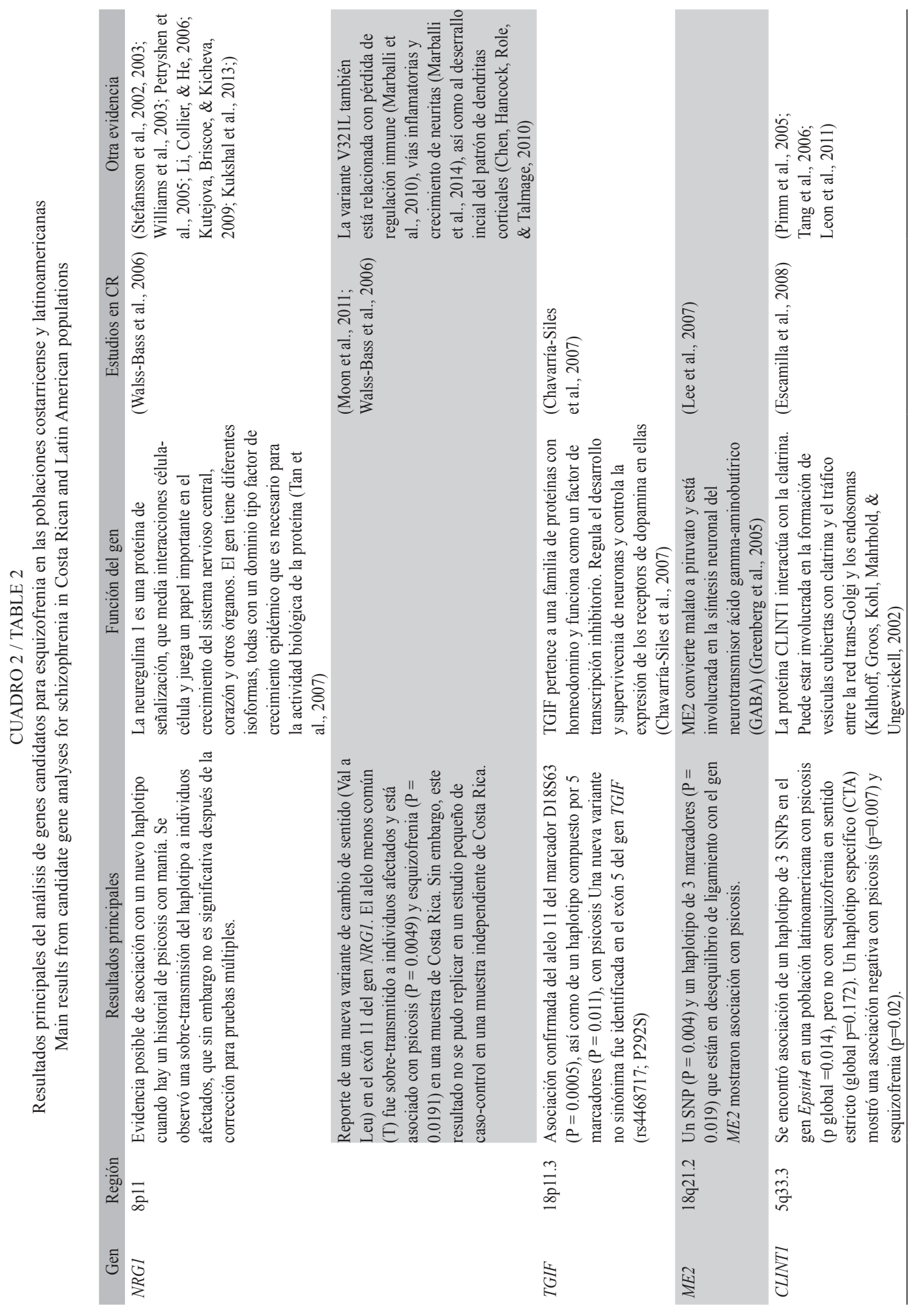

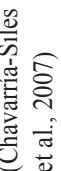

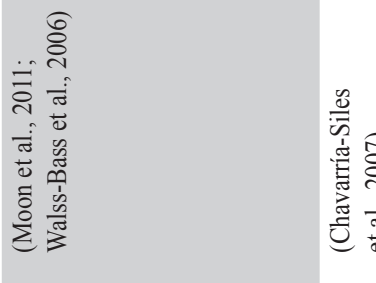

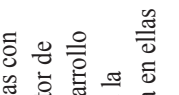

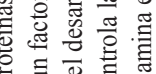

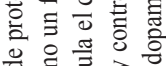

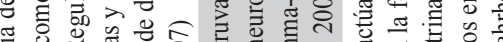

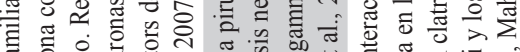

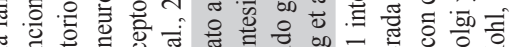

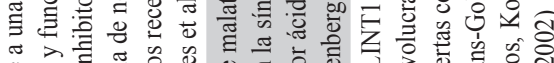

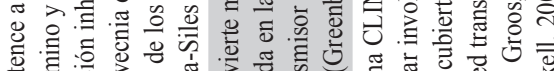

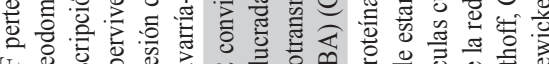

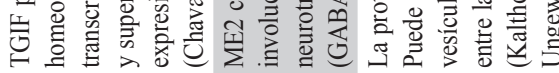

象 n 荧

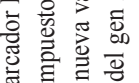

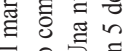

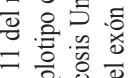

은 矛造 击

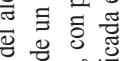

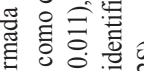

范 11.

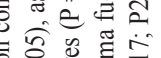

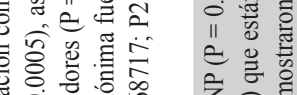

ठ․

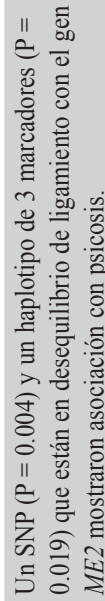

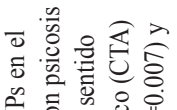

苔

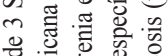

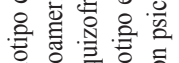

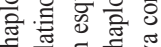

引

ष

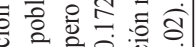

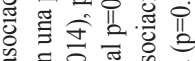

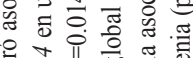

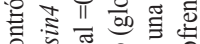

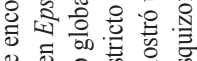

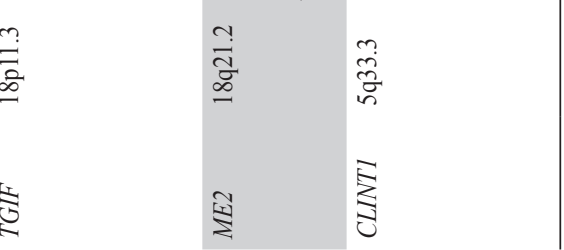




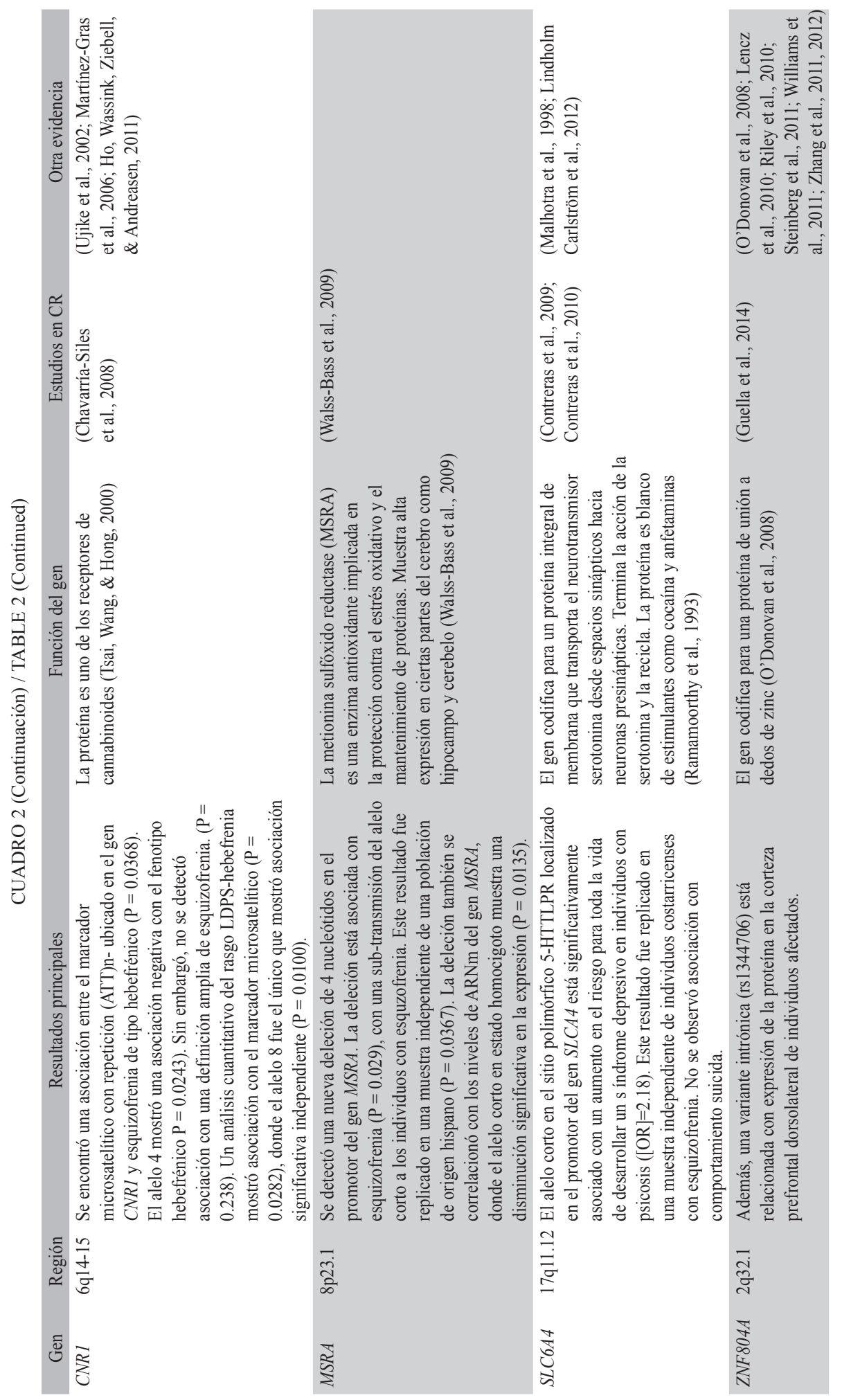




\section{CUADRO 3}

Resultados principales de los estudios de tamizaje genómico para trastorno bipolar tipo I en la población costarricense

TABLE 3

Main results from genomic screening studies for bipolar disorder type I in the Costa Rican population

\begin{tabular}{|c|c|c|c|c|}
\hline Región & Resultados principales & Diseño del estudio & Tipo de marcador & Referencias \\
\hline $1 \mathrm{p} 33$ & $\begin{array}{l}\text { Ligamiento sugerente con el marcador } \\
\text { rs } 1877734 \text { LOD }=2.31\end{array}$ & Familia grande & SNP & (Service et al., 2006) \\
\hline $2 q 13-14$ & Ligamiento sugerente NPL $=1.71$ & Familias & SNP & (Gonzalez et al., 2014) \\
\hline $5 q 31-33$ & $\begin{array}{l}\text { Reporte de un haplotipo informativo } \\
\text { de } 5 \text { marcadores, que es más frecuente } \\
\text { en individuos afectados. Confirmación } \\
\text { posterior con marcadores adicionales. } \\
\text { Un estudio de seguimiento con familias } \\
\text { de Colombia y Costa Rica identificó } \\
\text { un pico de ligamiento no paramétrico } \\
\text { en el marcador D5S2049 (NPL }=4.395 \text {, } \\
\mathrm{P}=0.00004) \text {. Un estudio posterior con } \\
\text { SNPs encontró un puntaje LOD }>4 \text { en } \\
\text { rs10035961, rs7721142 y rs } 1422795 \text {, } \\
\text { y LOD }>3 \text { en rs } 253602 \text {, rs } 142279 \text { y } \\
\text { rs10035961; así como una señal positiva } \\
\text { de asociación para rs } 244960(\mathrm{P}=0.00032) \\
\text { en la población de Costa Rica. }\end{array}$ & Familia grande, dúos y tríos & Microsatélite & $\begin{array}{l}\text { (Garner et al., 2001; Hong et } \\
\text { al., 2004; Herzberg et al., 2006; } \\
\text { Jasinska et al., 2009) }\end{array}$ \\
\hline $6 \mathrm{q} 14$ & $\begin{array}{l}\text { Ligamiento sugerente para el marcador } \\
\text { rs } 1180237 \text { LOD }=2.78\end{array}$ & Familia grande & SNP & (Service et al., 2006) \\
\hline $8 \mathrm{p} 23.1$ & $\begin{array}{l}\text { Reporte de dos haplotipos extendidos entre } \\
\text { D8S503 y D8S520 en región de 22cM } \\
\text { en el cromosoma } 8 \text {, que muestran sobre- } \\
\text { transmisión a individuos afectados }\end{array}$ & eTríos & STR & (Ophoff et al., 2002) \\
\hline $8 \mathrm{q} 24$ & $\begin{array}{l}\text { Señal significativa, pico más alto con } \\
\mathrm{LOD}=3.53, \mathrm{P}=2.78 \times 10^{-5}\end{array}$ & Familias & SNP & (Gonzalez et al., 2014) \\
\hline $11 \mathrm{p} 13-14$ & $\begin{array}{l}\text { Dos marcadores contiguos superaron en } \\
\text { umbral para el juego de datos combinados }\end{array}$ & Familia extendida & Microsatélite & (McInnes et al., 1996) \\
\hline $14 q 32$ & NPL y LOD $>2.65, \mathrm{P}<0.05$ & Familias & SNP & (Gonzalez et al., 2014) \\
\hline $16 \mathrm{q}$ & El marcador D16S486 superó el umbral & Extended pedigree & Microsatélite & (McInnes et al., 1996) \\
\hline $18 q 22-23$ & $\begin{array}{l}\text { Tres marcadores significativos en el juego } \\
\text { de datos combinados. Confirmado por } \\
\text { otros estudios con más marcadores, o un } \\
\text { análisis estadístico distinto. }\end{array}$ & $\begin{array}{l}\text { Familias extendidas, } \\
\text { probandos y miembros de la } \\
\text { familia }\end{array}$ & Microsatélite & $\begin{array}{l}\text { (Freimer, Reus, Escamilla, } \\
\text { McInnes et al., 1996; McInnes et } \\
\text { al., 1996; Escamilla et al., 1999, } \\
\text { 2001; Garner et al., 2001) }\end{array}$ \\
\hline $18 \mathrm{p} 11.3$ & $\begin{array}{l}\text { Señal para un haplotipo compartido } \\
\text { que abarca los exones } 7 \text { a } 11 \text { del gen } \\
\text { CLULI. Además, } 5 \text { marcadores mostraron } \\
\text { asociación con la enfermedad. }\end{array}$ & $\begin{array}{l}\text { Familias extendidas, } \\
\text { probandos y miembros de la } \\
\text { familia y controles }\end{array}$ & STR y SNPs & (McInnes et al., 2001) \\
\hline $18 \mathrm{p} 11.32$ & $\begin{array}{l}\text { Evidencia sugerente pero no significativa } \\
\text { de ligamiento con D18S59 y el marcador } \\
\text { cercano D18S476 }\end{array}$ & $\begin{array}{l}\text { Familia extendida, probandos } \\
\text { y miembros de la familia }\end{array}$ & s Microsatélite & $\begin{array}{l}\text { (McInnes et al., 1996; Escamilla } \\
\text { et al., 1999) }\end{array}$ \\
\hline $21 \mathrm{p} 12$ & $\begin{array}{l}\text { Puntaje sugerente de ligamiento para } \\
\text { marcador rs } 12034 \mathrm{LOD}=2.21\end{array}$ & Familia grande & SNP & (Service et al., 2006) \\
\hline
\end{tabular}

Las señales positivas o sugerentes para asociación y/o ligamiento se presentan de acuerdo con el tipo de estudio, tipo de marcador y fenotipo.

Positive or suggestive signals of linkage/association are presented according to type of study, marker used, and phenotype. 
trastornos, lo cual podría implicar la necesidad de reconsiderar los criterios estándar de diagnóstico que se usan para los estudios genéticos, como mencionamos al inicio (Walss-Bass et al., 2005; Service et al., 2006). Sin embargo, únicamente dos de los genes candidatos con una asociación positiva en la muestra costarricense con esquizofrenia fueron evaluados para el trastorno bipolar y para ninguno se encontró evidencia de que jueguen un papel en la etiología de este último trastorno ( $N R G 1$ : Moon et al., 2011; ZNF804A: Guella et al., 2014).

Con base en los resultados reportados para el gen $C A C N A 1 C$ por otros grupos que estudian la genética del trastorno bipolar (Ferreira et al., 2008; Sklar et al., 2008; Liu et al., 2011), González y colaboradores (2013) utilizaron una estrategia basada en familias latinas (incluyendo 38 familias costarricenses) para detectar asociación con variantes en este gen. Dos de los SNPs reportados anteriormente no estuvieron asociados significativamente con la enfermedad en este estudio, pero se encontraron cuatro haplotipos en el gen $C A C N A 1 C$ que mostraron asociación significativa con el trastorno bipolar en población latina (Gonzalez et al., 2013b).

En otro estudio con las mismas poblaciones latinas, Gonzalez y colaboradores (2013a) intentaron determinar si el gen $A N K 3$ es relevante para la patología de la enfermedad. Para lograr esto, se identificaron en tríos de México y Centroamérica su genotipo para varios SNPs dentro de la región del gen $A N K 3$. No se logró replicar la asociación reportada en estudios previos para SNPs individuales (rs9804190 and rs 10994336; (Schulze et al., 2009). Sin embargo, cuando rs 10994336 fue analizado en el contexto de un haplotipo de 5 loci se encontró una asociación positiva con la enfermedad. Estos resultados, junto con publicaciones por otros grupos (Schulze et al., 2009; Schizophrenia Psychiatric Genome-Wide Association Consortium, 2011; Sklar et al., 2011) sugieren que la variación en los genes $C A C N A 1 C$ y $A N K 3$ juega un papel importante en la arquitectura genética del trastorno bipolar.

\section{Trastorno obsesivo compulsivo, Déficit Atencional y Síndrome de Tourette}

El trastorno obsesivo compulsivo es un trastorno psiquiátrico altamente heterogéneo que se caracteriza por pensamientos intrusivos y miedos, acompañados por un comportamiento repetitivo ritualizado (American Psychiatric Association, 2000). Tiene una prevalencia de alrededor de 1.1-1.2 \% (Ruscio, Stein, Chiu, \& Kessler, 2010; Torres et al., 2006), presenta patrones complejos de síntomas que pueden no traslaparse entre individuos y pueden incluso variar en el mismo individuo (Leckman et al., 1997; van Grootheest, Cath, Beekman, \& Boomsma, 2005). Se acepta que, al menos hasta cierto punto, hay un componente genético que influye sobre el riesgo de desarrollar la enfermedad (van Grootheest et al., 2005). Sin embargo, la dificultad para establecer un fenotipo homogéneo y etiológicamente relevante ha complicado la búsqueda de genes de vulnerabilidad (Miguel et al., 2005).

Dado que la población hispana está subrepresentada en los estudios epidemiológicos del trastorno obsesivo compulsivo y debido a su fenotipo heterogéneo, Chavira y colaboradores (2008) compararon la expresión de síntomas tempranos del trastorno obsesivo compulsivo en una población latina del Valle Central de Costa Rica con una población de California. El objetivo del estudio fue identificar aspectos de la enfermedad que pueden variar de acuerdo factores culturales, así como la percepción de la enfermedad. Los resultados sugieren que los principales componentes fenotípicos del trastorno son comparables en ambas muestras, y por lo tanto podrían tener una base biológica. Sin embargo, existe una diferencia en el nivel de discapacidad que causa la enfermedad, donde la muestra costarricense mostró una severidad menor de los síntomas y una menor tasa de trastornos del ánimo que ocurren junto con la enfermedad (Chavira et al., 2008).

Otro estudio con esa misma muestra mostró que el déficit atencional es más frecuente en niños diagnosticados con trastorno obsesivo 
compulsivo que en la población general. (11\% vs $5 \% \mathrm{P}=0.005$ ) (Sheppard et al., 2010). En una investigación independiente, se encontró una prevalencia de $5 \%$ para el déficit atencional en una muestra de niños costarricenses de edad escolar (Berrocal et al., 2011), lo cual confirma el aumento en prevalencia en la muestra con trastorno obsesivo compulsivo reportado por Sheppard y colaboradores (2010).

Con el objetivo de reducir el ruido introducido a los análisis genéticos cuando el fenotipo de estudio es complejo y heterogéneo, Ross y colaboradores (2011) realizaron un análisis de ligamiento en tres genealogías grandes del Valle Central de Costa Rica con múltiples individuos afectados para identificar posibles regiones genómicas involucradas en la etiología del trastorno obsesivo compulsivo de inicio temprano. Se identificaron tres regiones cromosómicas de interés, $15 \mathrm{q} 14(\mathrm{LOD}=3.13)$, $1 \mathrm{p} 21(\mathrm{LOD}=2.16)$ y $16 \mathrm{q} 24(\mathrm{LOD}=2.15)$, y seguidamente se realizó un análisis de secuencia más profundo de la región $15 q 14$. Se identificó una región de interés de $7 \mathrm{Mb}$ en el intrón 1 del gen para el receptor de rianodina 3 (RYR3), que está definida por un haplotipo delimitado por los SNPs rs1520942 y rs1003223 (Ross et al., 2011). Después de secuenciar los exones de $R Y R 3$, así como algunas regiones intrónicas, se identificaron variantes de las cuales ninguna segregó perfectamente con el haplotipo identificado en las tres familias. Este estudio replicó los hallazgos de (Shugart et al., 2006), y proporciona evidencia adicional de que esta región del cromosoma 15 está involucrada en la susceptibilidad genética a este trastorno. Además, en un estudio que cuantificó la heredabilidad atribuible a variantes en todo el genoma para el trastorno obsesivo compulsivo, se encontró que el cromosoma 15 fue el único que incluye una mayor proporción de la heredabilidad para el trastorno que la esperada con base en el número de SNPs o el número de genes del cromosoma (Davis et al., 2013).

El síndrome de Tourette es otro trastorno psiquiátrico que se caracteriza por tics motores y vocales. Algunos estudios han sugerido que existen factores genéticos compartidos entre este trastorno y el trastorno obsesivo compulsivo (Mathews \& Grados, 2011), mientras que otros han identificado diferencias en la arquitectura genética de ambos trastornos (Davis et al., 2013; Yu et al., 2015). Tal como en el caso del trastorno obsesivo compulsivo, el fenotipo básico del síndrome de Tourette en Costa Rica parece coincidir con lo observado en el resto del mundo, donde las diferencias culturales juegan un papel pequeño en el grado de discapacidad percibido, pero con poca variación en sintomatología (Mathews et al., 2001). Otro estudio llevado a cabo con la población costarricense proporcionó evidencia a favor de un perfil común de síntomas, que podría ser interesante en el contexto de analizar la contribución de la variación genética con la etiología de la enfermedad (Mathews et al., 2007).

Los resultados presentados anteriormente enfatizan la dificultad para establecer un fenotipo homogéneo, convincente y etiológicamente relevante para el desarrollo de estudios genéticos, y este aspecto muy probablemente ha contribuido a que la identificación de genes de susceptibilidad siga siendo un reto. Sin embargo, se han hecho esfuerzos por identificar la arquitectura genética del síndrome de Tourette. Un estudio grande de asociación de todo el genoma que fue llevado a cabo por Scharf y colaboradores (2013) en diferentes poblaciones con ancestría europea no logró identificar una señal significativa a nivel de todo el genoma para asociación con el síndrome de Tourette, pero la señal principal se obtuvo con rs 7868992 en el cromosoma 9q32. Un análisis posterior con dos poblaciones latinas de Colombia y Costa Rica también identificó a este SNP como la principal señal de asociación ( $\mathrm{P}$ combinada $\left.=2.94 \times 10^{-8}\right)$. Aunque estos resultados sugieren a rs 7868992 como un posible candidato, el hallazgo debería ser replicado en una muestra más grande y con el poder necesario para que el SNP sea considerado como una variante de susceptibilidad (Scharf et al., 2013).

Un estudio llevado a cabo por Abelson et al. (2005) sugirió a SLITRK1 (13q31.1) como un posible gen candidato de susceptibilidad al síndrome de Tourette. Encontraron dos 
variantes que estaban ausentes en los controles: una variante de alteración del marco de lectura y una variante en el sitio de unión de miR-189. Sin embargo, ninguno de estos resultados pudo ser replicado en un análisis con muestras de una población de Costa Rica y una ashkenazi (Estados Unidos) (Keen-Kim et al., 2006). Los autores de esta segunda investigación sugieren que el primer reporte de asociación pudo ser un falso positivo, posiblemente debido al efecto de estratificación en casos y controles (Keen-Kim et al., 2006).

\section{Autismo}

El autismo es considerado un trastorno del neurodesarrollo de etiología compleja, cuyas características fenotípicas varían dentro de un espectro de síntomas que incluyen capacidades limitadas en la estructura del lenguaje, anomalías en el desarrollo social y comportamientos rígidos y repetitivos (Folstein \& Rosen-Sheidley, 2001). Aunque los casos familiares de autismo son poco comunes, son más frecuentes de lo esperado al azar y el riesgo de autismo en hermanos de una persona afectada es mayor que la prevalencia de la población (Risch et al., 1999). Este riesgo aumentado en familiares se hace especialmente evidente cuando se analizan características del lenguaje y/o rasgos cuantitativos (como respuesta social) en individuos aparentemente sanos en familias con incidencia múltiple de afectados (Constantino, Zhang, Frazier, Abbacchi, \& Law, 2010). La concordancia elevada en gemelos monocigóticos $(82 \%)$ cuando se compara con gemelos dicigóticos $(10 \%)$ se considera como evidencia a favor de un papel importante de los factores genéticos en el desarrollo de la enfermedad, y se han estimado valores de heredabilidad que alcanzan el 90 \% (Folstein \& Rosen-Sheidley, 2001). Existen algunos reportes de estudios de ligamiento para autismo y han encontrado múltiples regiones asociadas con la enfermedad, lo que sugiere la arquitectura genética típica de las enfermedades complejas (para una revisión ver Folstein \& Sheidley, 2001). Además, en los últimos años se ha identificado que las variantes codificantes de novo juegan un papel importante en la base genética del espectro de autismo (Ronemus, Iossifov, Levy, \& Wigler, 2014).

En una evaluación clínica inicial en la población de Costa Rica se encontró que las características generales medidas por las pruebas diagnósticas (ADOS y ADI-R) son similares a las que se encuentran en otros países. La única diferencia encontrada fue que un porcentaje menor de los individuos presentaron un coeficiente intelectual normal en comparación con otros reportes (17\% vs $25 \%$ ). Sin embargo, esto podría deberse a un sesgo de reclutamiento hacia fenotipos más severos, o a problemas con la aplicación de la prueba de coeficiente intelectual, y no representar una caracerística fenotípica de importancia biológica (McInnes et al., 2005).

Con frecuencia se han reportado anomalías cromosómicas en individuos con autismo (Marshall et al., 2008), por lo cual se han realizado dos estudios en Costa Rica para analizar este aspecto. McInnes y colaboradores (2010) encontraron variantes en el número de copias (CNVs) en la región cromosómica 15q24 en 14 individuos diagnosticados con trastorno en el espectro de autismo. Uno de ellos tiene una deleción de novo atípica en 15q23-q24.1, lo cual permite reducir la región de interés y el número de genes candidatos en esa región (McInnes et al., 2010). Un reporte de caso de un niño con autismo y retraso severo en el lenguaje detectó la presencia de una duplicación en $17 \mathrm{p} 11.2$, lo que sugiere que un gen involucrado en desarrollo del lenguaje puede estar ubicado en este región (Nakamine et al., 2008). De las variantes que se han reportado como asociadas a trastornos psiquiátricos en la población costarricense, únicamente la variante de cambio de sentido en el exón 11 del gen NRG1 fue analizada en el contexto de autismo, y no se detectó asociación (McInnes et al., 2007). Como dato interesante, se ha encontrado que el gen miR-137 que se asocia con esquizofrenia, también muestra asociación con autismo (Zhao \& Nyholt, 2017). Como objetivo a futuro, sería deseable hacer un estudio de 
asociación de variantes en miR-137 y autismo en la muestra costarricense.

\section{Enfermedad de Alzheimer}

La enfermedad de Alzheimer es un trastorno neurodegenerativo progresivo y es la principal causa de demencia. Se caracteriza por una disminución progresiva en funciones cognitivas que lleva a una completa dependencia para las actividades diarias. En Costa Rica, ante el aumento proporcional en la población de individuos de edades avanzadas y su riesgo para el desarrollo de este tipo de demencia, la enfermedad de Alzheimer representa una carga con un costo elevado. El sistema de salud pública está empezando a dedicar recursos para instaurar programas de tamizaje para enfermedades neurodegenerativas (Wesseling et al., 2013). Esto es especialmente importante dado que se espera que la prevalencia global general de demencia se duplique cada 20 años (Reitz, Brayne, \& Mayeux, 2011). Se considera que la enfermedad tiene una etiología compleja, donde tanto los genes como el ambiente juegan un papel importante en su desarrollo (Reitz et al., 2011; Mayeux \& Stern, 2012). El principal factor de riesgo en casos esporádicos de enfermedad de Alzheimer es un haplotipo en el gen que codifica para apolipoproteína E (APOE), $\mathrm{y}$ ha sido replicado en múltiples estudios (Lambert \& Amouyel, 2011). La asociación del alelo $\& 4$ del gen $A P O E$ y su interacción con la edad fueron evaluadas por Valerio et al. (2014) en una muestra de casos y controles de la población de Costa Rica. Se encontró que el alelo $\varepsilon 4$ está asociado con demencia en los individuos de menos de 90 años $\left(\mathrm{X}^{2}=12.35\right.$, $\mathrm{df}=1, \mathrm{P}<0.001 ; \mathrm{OR}=7.03, \mathrm{CI}=2.07,23.82$ ). Sin embargo, como se ha mostrado en estudios previos (Farrer et al., 1997), esta asociación se pierde en el grupo de edad más avanzada, lo cual sugiere un modelo de sobrevivientes para el envejecimiento cognitivo exitoso en edades avanzadas extremas (Valerio et al., 2014).

\section{DISCUSIÓN}

El estudio de la base genética de los trastornos psiquiátricos, y en general de las enfermedades complejas, representa un fuerte reto debido a la existencia de múltiples factores genéticos de riesgo y un papel determinante de factores ambientales para el desarrollo de estas. En la investigación en estos temas se ha visto una evolución en el tiempo en las estrategias utilizadas. Inicialmente se trabajó con individuos emparentados (familias, parejas de hermanos) y se realizaron análisis de ligamiento. Los primeros esfuerzos de mapeo genético para trastornos psiquiátricos en Costa Rica fueron estudios de ligamiento. Sin embargo, aunque esta estrategia ha sido altamente exitosa para enfermedades con herencia mendeliana, no ha sucedido lo mismo con las enfermedades complejas (Altshuler, Daly, \& Lander, 2008). Posteriormente se desarrollaron un gran número de estudios de asociación genética a nivel de todo el genoma (GWAS) para muchas enfermedades y con tamaños de muestra en el orden de miles de individuos. El objetivo de estos GWAS es identificar variantes genéticas relativamente comunes que aporten al riesgo de desarrollar los distintos trastornos (Visscher et al., 2017). El estudio genético de los trastornos psiquiátricos no ha sido la excepción. El gran número de estudios tipo GWAS en esta área ha resultado en la identificación de más de 200 loci con significancia a nivel de todo el genoma que contribuyen al riego de desarrollar enfermedad mental (Sullivan et al., 2017). En Costa Rica, los estudios de asociación para estos trastornos se desarrollaron con base en un diseño experimental con tríos (padres con un hijo afectado). Los GWAS han demostrado que los trastornos psiquiátricos son altamente poligénicos, con altos números de loci involucrados, la mayoría de los cuales tienen un efecto pequeño o muy pequeño sobre el riesgo de desarrollar la enfermedad. Desafortunadamente, en la mayoría de los loci identificados por medio de GWAS no 
se han identificado genes de riesgo para enfermedad mental (Manolio, 2010; Seifuddin et al., 2012). Además, se sugiere que la mayoría de las variantes más frecuentes de efecto menor que es posible detectar (porque el tamaño de su efecto es suficientemente grande para que sea estadísticamente significativo en los estudios de GWAS y tamaño de muestras posible) ya se han detectado.

La evidencia reciente sugiere que las variantes raras de efecto mediano o fuerte están involucradas una proporción importante de las enfermedades humanas (McClellan \& King, 2010). Estas variantes poco comunes pueden contribuir a explicar parte de la heredabilidad faltante, la arquitectura genética, biología y fisiopatología de los trastornos mentales mayores. Entre estas están los CNVs, las mutaciones de novo (que no están presentes en los padres) y los SNPs muy poco comunes que se presentan en pocas familias. A diferencia de los SNPs implicados en los GWAS, las variantes raras, especialmente las de pérdida de función de un gen o que afectan la expresión de la proteína, proporcionan evidencia más directa de la relación biológica entre un gen y un fenotipo (Marouli et al., 2017; MacArthur et al., 2012; Veltman \& Brunner, 2012). Existe actualmente, por lo tanto, una tendencia al regreso a estudios con familias en búsqueda de variantes raras. Un estudio nuestro vigente consiste en secuenciar el genoma completo en familias con al menos tres casos de trastornos mentales mayores (bipolar y esquizofrenia) y va en la línea de buscar CNVs y SNPs poco comunes e incluso privados (Glahn et al., 2018). Los tríos inicialmente reclutados hace 20 años van a ser útiles para la búsqueda de variantes de novo.

Por sus características, se sabe que las variantes raras tienen pocas aplicaciones clínicas (presentes en unas pocas o incluso una familia). La pretensión es que puedan contribuir a explicar vías biológicas y mejorar nuestro conocimiento acerca del desarrollo de trastornos psiquiátricos. Las familias también sirven para integrar el estudio de los factores ambientales contribuyentes. Si se logra descubrir variantes raras en algunas de ellas, es posible estudiar factores protectores y de riesgo psicosociales en estas familias. Como predeciblemente van a ser variantes muy raras, la forma de demostrar el resultado no es por estudios poblacionales sino por estudios de predicción bioinformática y estudios funcionales a nivel celular y con animales. Ya hemos iniciado este tipo de estudio (con líneas celulares y células madre pluripotentes inducidas o iPS) para variantes descubiertas en Costa Rica, como la sustitución de valina a leucina en el exón 11 del gen NRG1 (Walss-Bass et al., 2006).

Estos estudios en familias también abordan el reto de que la clasificación de trastornos psiquiátricos según la categorización actual, que separa el trastorno bipolar y la esquizofrenia, no necesariamente refleja la biología y etiopatogenia de estas condiciones. Por lo anterior, hemos implementado otras estrategias para clasificar y categorizar a las personas con instrumentos como pruebas cognitivas y escalas psicológicas que no son dicotómicas (afectados/ no afectados), sino cuantitativas. También utilizamos clasificaciones sindrómicas y no diagnósticas, como es la presencia de psicosis, común al trastorno bipolar y la esquizofrenia.

La evolución de las estrategias de investigación en Costa Rica ha dado así un círculo completo. Se inició con el estudio de familias grandes con los pocos marcadores genéticos de los que se disponía en ese momento, seguido por los estudios de parejas de hermanos afectados y estudios de asociación en tríos, con 800-1000 SNPs repartidos por todo el genoma. En la actualidad, la accesibilidad de la secuenciación de genoma completo hace posible el regreso a estudios con familias en busca de estas variantes raras que alteran potencialmente el funcionamiento de una proteína y tienen un efecto mayor al muy pequeño efecto de las variantes de los estudios GWAS.

Por último, es importante enfatizar que estudios genéticos en un país latinoamericano como Costa Rica tienen el valor de aportar información acerca de poblaciones que usualmente no han sido incluidas en los estudios de enfermedades complejas. La mayoría de las variantes descritas han sido identificadas 
en población europea, y en menor grado asiática, pero existe un vacío de información de poblaciones africanas y latinoamericanas que nuestras investigaciones están contribuyendo a subsanar. Nuestro grupo de investigación en psiquiatría genética ha contado en un cuarto de siglo con la colaboración de muchos investigadores y un gran número de estudiantes. Los resultados producidos por el grupo han sido posibles gracias a un constante trabajo colaborativo, internacional y multidisciplinario.

Declaración de ética: los autores declaran que todos están de acuerdo con esta publicación y que han hecho aportes que justifican su autoría; que no hay conflicto de interés de ningún tipo; y que han cumplido con todos los requisitos y procedimientos éticos y legales pertinentes. Todas las fuentes de financiamiento se detallan plena y claramente en la sección de agradecimientos. El respectivo documento legal firmado se encuentra en los archivos de la revista.

\section{AGRADECIMIENTOS}

A las muchas personas de las familias que voluntariamente han participado en las distintas investigaciones a lo largo de 25 años. A la Universidad de Costa Rica y a los entes que han financiado las investigaciones: National Institute of Health (NIH), Alzheimer Foundation, International Centre for Genetic Engineering and Biotechnology (ICGEB), Brain and Behavior Research Foundation y UCR.

\section{RESUMEN}

El estudio de la base genética de los trastornos neuropsiquiátricos se inició en Costa Rica hace más de 25 años. En este tiempo se han realizado investigaciones enfocadas en diferentes trastornos: esquizofrenia, trastorno bipolar, demencia de Alzheimer, trastorno obsesivo compulsivo, trastorno obsesivo compulsivo, trastorno por déficit de atención y síndrome de Tourette. Los estudios realizados han tenido una amplia variación en lo que se refiere a diseño (ligamiento/asociación), muestra utilizada (familias/parejas de hermanos afectados/tríos), cobertura genómica (estudios con genes candidatos/tamizajes de todo el genoma) y definición del fenotipo (categoría diagnóstica/clasificación sindrómica/endofenotipo). Presentamos un resumen de los principales hallazgos genómicos obtenidos en estos estudios multidisciplinarios y discutimos la importancia, lecciones y retos de la investigación genética en trastornos psiquiátricos complejos.

Palabras clave: psiquiatría; cerebro; mapeo genético; fenotipo; endofenotipo; gen.

\section{REFERENCIAS}

Abecasis, G. R., Burt, R. A, Hall, D., Bochum, S., Doheny, K. F., Lundy, S. L., ... Karayiorgou, M. (2004). Genomewide scan in families with schizophrenia from the founder population of Afrikaners reveals evidence for linkage and uniparental disomy on chromosome 1. American Journal of Human Genetics, 74(3), 403-417. DOI: 10.1086/381713

Abelson, J. F., Kwan, K. Y., O'Roak, B. J., Baek, D. Y., Stillman, A. A, Morgan, T. M., ... State, M. W. (2005). Sequence variants in SLITRK1 are associated with Tourette's syndrome. Science, 310(5746), $317-$ 320. DOI: $10.1126 /$ science. 1116502

Altshuler, D., Daly, M. J., \& Lander, E. S. (2008). Genetic Mapping in Human Disease. Science, 322(5903), 881-888. DOI: 10.1126/science.1156409

American Psychiatric Association. (2000). Diagnostic and Statistical Manual of Mental Disorders, Fourth Edition, Text Revision (DSM-IV-TR) (4th ed., Vol. 1). Arlington, VA: American Psychiatric Association. DOI: 10.1176/appi.books. 9780890423349

Andreasen, N. C. (1995). Symptoms, signs, and diagnosis of schizophrenia. Lancet, 346(8973), 477-481.

Ávila, A. (2018). Asociación entre el número de copias del VNTR del promotor interno del exón 3 del gen MIR137HG y la edad de inicio de la esquizofrenia en el Valle Central de Costa Rica (Tesis de Licenciatura). Universidad de Costa Rica, San José, Costa Rica.

Badner, J. A., Koller, D., Foroud, T., Edenberg, H., Nurnberger, J. I., Zandi, P. P., ... Byerley, W. (2012). Genome-wide linkage analysis of 972 bipolar pedigrees using single-nucleotide polymorphisms. Molecular Psychiatry, 17(8), 818-826. DOI: 10.1038/ mp.2011.89

Barnett, J. H., \& Smoller, J. W. (2009). The genetics of bipolar disorder. Neuroscience, 164(1), 331-343. DOI: $10.1016 /$ j.neuroscience.2009.03.080

Bauer, M., \& Pfennig, A. (2005). Epidemiology of bipolar disorders. Epilepsia, 46(Suppl. 4), 8-13.

Bemis, L. T., Chen, R., Amato, C. M., Classen, E. H., Robinson, S. E., Coffey, D. G., ... Robinson, W. A. (2008). MicroRNA-137 targets microphthalmia-associated 
transcription factor in melanoma cell lines. Cancer Research, 68(5), 1362-1368. DOI: 10.1158/00085472.CAN-07-2912

Berrocal, M., Peskin, V., Weiss, N. T., Schuler, J., Monge, S., McGough, J. J., ... Mathews, C. (2011). Prevalencia y tamizaje del trastorno por déficit atencional con hiperactividad en Costa Rica. Revista Argentina de Psiquiatria, XXII, 337-342.

Beveridge, N J, Tooney, P. a, Carroll, A. P., Gardiner, E., Bowden, N., Scott, R. J., ... Cairns, M. J. (2008) Dysregulation of miRNA $181 \mathrm{~b}$ in the temporal cortex in schizophrenia. Human Molecular Genetics, 17(8), 1156-1168. DOI: $10.1093 / \mathrm{hmg} / \mathrm{ddn} 005$

Buizer-Voskamp, J. E., Muntjewerff, J.-W., Strengman, E., Sabatti, C., Stefansson, H., Vorstman, J. A. S., \& Ophoff, R. A. (2011). Genome-wide analysis shows increased frequency of copy number variation deletions in Dutch schizophrenia patients. Biological Psychiatry, 70(7), 655-662. DOI: 10.1016/j. biopsych.2011.02.015

Carmiol, N., Peralta, J. M., Almasy, L., Contreras, J., Pacheco, A., Escamilla, M. A., ... Glahn, D. C. (2014). Shared genetic factors influence risk for bipolar disorder and alcohol use disorders. European Psychiatry: The Journal of the Association of European Psychiatrists, 29(5), 282-287. DOI: 10.1016/j. eurpsy.2013.10.001

Chavarría-Siles, I., Contreras-Rojas, J., Hare, E., WalssBass, C., Quezada, P., Dassori, A., ... Escamilla, M. a. (2008). Cannabinoid receptor 1 gene (CNR1) and susceptibility to a quantitative phenotype for hebephrenic schizophrenia. American Journal of Medical Genetics, 147(3), 279-284. DOI: 10.1002/ ajmg.b.30592

Chavarría-Siles, I., Walss-Bass, C., Quezada, P., Dassori, a, Contreras, S., Medina, R., ... Escamilla, M. a. (2007). TGFB-induced factor (TGIF): a candidate gene for psychosis on chromosome 18p. Molecular Psychiatry, 12(11), 1033-1041. DOI: 10.1038/sj.mp.4001997

Chavira, D. A., Garrido, H., Bagnarello, M., Azzam, A., Reus, V. I., \& Mathews, C. A. (2008). A comparative study of obsessive-compulsive disorder in Costa Rica and the United States. Depression and Anxiety, 25(7), 609-619. DOI: 10.1002/da.20357

Chen, Y., Hancock, M. L., Role, L. W., \& Talmage, D. A (2010). Intramembranous valine linked to schizophrenia is required for neuregulin 1 regulation of the morphological development of cortical neurons. The Journal of Neuroscience, 30(27), 9199-9208. DOI: 10.1523/JNEUROSCI.0605-10.2010

Constantino, J. N., Zhang, Y., Frazier, T., Abbacchi, A. M., \& Law, P. (2010). Sibling recurrence and the genetic epidemiology of autism. The American Journal of Psychiatry, 167(11), 1349-1356. DOI: 10.1176/appi. ajp.2010.09101470
Contreras, J., Dassori, A., Medina, R., Raventos, H., Ontiveros, A., Nicolini, H., ... Escamilla, M. (2009). Diagnosis of schizophrenia in latino populations: a comparison of direct interview and consensus based multi-source methods. The Journal of Nervous and Mental Disease, 197(7), 530-535. DOI: 10.1097/ NMD.0b013e3181aac935

Contreras, J, Hare, L., Camarena, B., Glahn, D., Dassori, A., Medina, R., ... Escamilla, M. (2009). The serotonin transporter 5-HTTPR polymorphism is associated with current and lifetime depression in persons with chronic psychotic disorders. Acta Psychiatrica Scandinavica, 119(2), 117-127. DOI: 10.1111/j.1600-0447.2008.01273.x

Contreras, J., Hare, E., Chavarría, G., \& Raventós, H. (2018). Quantitative genetic analysis of anxiety trait in bipolar disorder. Journal of Affective Disorders, 225, 395-398. DOI: 10.1016/j.jad.2017.08.023

Contreras, J., Hare, E., Chavarría-Soley, G., \& Raventós, H. (2018). Genome-wide QTL analysis for anxiety trait in bipolar disorder type I. Journal of Affective Disorders, 234, 105-108. DOI: 10.1016/j. jad.2017.12.019

Contreras, J., Hare, E., Escamilla, M., \& Raventos, H. (2012). Principal domains of quantitative anxiety trait in subjects with lifetime history of mania. Journal of Affective Disorders, 136(1-2), e69-75. DOI: 10.1016/j.jad.2011.06.036

Contreras, J., Hare, E., Pacheco, A., Escamilla, M., \& Raventos, H. (2010). Is subclinical anxiety an endophenotype for bipolar I patients? A study from a Costa Rican sample. Journal of Affective Disorders, 122(3), 267-272. DOI: 10.1016/j.jad.2009.07.017

Contreras, J., Hernández, S., Quezada, P., Dassori, A., Walss-Bass, C., Escamilla, M., \& Raventos, H. (2010). Association of serotonin transporter promoter gene polymorphism (5-HTTLPR) with depression in Costa Rican schizophrenic patients. Journal of Neurogenetics, 24(2), 83-89. DOI: $10.3109 / 01677060903583994$

Cooper-Casey, K., Mésen-Fainardi, A., Galke-Rollins, B., Llach, M., Laprade, B., Rodriguez, C., ... Byerley, W. (2005). Suggestive linkage of schizophrenia to $5 \mathrm{p} 13$ in Costa Rica. Molecular Psychiatry, 10(7), 651-656. DOI: $10.1038 /$ sj.mp.4001640

Craddock, N., \& Sklar, P. (2013). Genetics of bipolar disorder. Lancet, 381(9878), 1654-1662. DOI: 10.1016/ S0140-6736(13)60855-7

Davis, L. K., Yu, D., Keenan, C. L., Gamazon, E. R., Konkashbaev, A. I., Derks, E. M., ... Scharf, J. M. (2013). Partitioning the heritability of Tourette syndrome and obsessive compulsive disorder reveals differences in genetic architecture. PLOS Genetics, 9(10), e1003864. DOI: 10.1371/journal. pgen. 1003864 
DeLisi, L. E., Mesen, A., Rodriguez, C., Bertheau, A., LaPrade, B., Llach, M., ... Sherrington, R. (2002). Genome-wide scan for linkage to schizophrenia in a Spanish-origin cohort from Costa Rica. American Journal of Medical Genetics, 114(5), 497-508. DOI: 10.1002/ajmg. 10538

Escamilla, M., Hare, E., Dassori, A. M., Peralta, J. M., Ontiveros, A., Nicolini, H., ... Almasy, L. (2009). A schizophrenia gene locus on chromosome 17q21 in a new set of families of Mexican and central american ancestry: evidence from the NIMH Genetics of schizophrenia in latino populations study. The American Journal of Psychiatry, 166(4), 442-449. DOI: 10.1176/appi.ajp.2008.08040612

Escamilla, M., Lee, B. D., Ontiveros, A., Raventos, H., Nicolini, H., Mendoza, R., ... Dassori, A. (2008). The epsin 4 gene is associated with psychotic disorders in families of Latin American origin. Schizophrenia Research, 106(2-3), 253-257. DOI: 10.1016/j. schres.2008.09.005

Escamilla, M. A., McInnes, L. A., Service, S. K., Spesny, M., Reus, V. I., Molina, J., ... Freimer, N. B. (2001). Genome screening for linkage disequilibrium in a Costa Rican sample of patients with bipolar-I disorder: a follow-up study on chromosome 18. American Journal of Medical Genetics, 105(2), 207-213.

Escamilla, M. A., McInnes, L. A., Spesny, M., Reus, V. I., Service, S. K., Shimayoshi, N., ... Freimer, N. B. (1999). Assessing the feasibility of linkage disequilibrium methods for mapping complex traits: an initial screen for bipolar disorder loci on chromosome 18 . American Journal of Human Genetics, 64(6), 16701678. DOI: $10.1086 / 302400$

Escamilla, M, Ontiveros, A., Nicolini, H., Raventos, H., Mendoza, R., Medina, R., ... Almasy, L. (2007). A genome-wide scan for schizophrenia and psychosis susceptibility loci in families of Mexican and Central American ancestry. American Journal of Medical Genetics. Part B, Neuropsychiatric Genetics: The Official Publication of the International Society of Psychiatric Genetics, 144B(2), 193-199. DOI: 10.1002/ajmg.b.30411

Escamilla, M. A., Spesny, M., Reus, V. I., Gallegos, A., Meza, L., Molina, J., ... Freimer, N. B. (1996). Use of linkage disequilibrium approaches to map genes for bipolar disorder in the Costa Rican population. American Journal of Medical Genetics, 67(3), 244-253. DOI: 10.1002/ (SICI) 1096-8628(19960531)67:3<244::AIDAJMG2>3.0.CO;2-N

Fallin, M. D., Lasseter, V. K., Liu, Y., Avramopoulos, D., McGrath, J., Wolyniec, P. S., ... Pulver, A. E. (2011). Linkage and association on 8p21.2-p21.1 in schizophrenia. American Journal of Medical Genetics. Part B, Neuropsychiatric Genetics : The Official Publication of the International Society of Psychiatric Genetics, 156(2), 188-197. DOI: 10.1002/ajmg.b.31154
Farrer, L., Cupples, L., Haines, J., Hyman, B., Kukull, W., Mayeux, R., ... van Dujin, C. (1997). Effects of age, sex, and ethnicity on the association between apolipoprotein E genotype and Alzheimer disease: a meta-analysis. Jama, 278(16), 1349. DOI: 10.1001/ jama.1997.03550160069041

Ferreira, M. A. R., O’Donovan, M. C., Meng, Y. A., Jones, I. R., Ruderfer, D. M., Jones, L., ... Craddock, N. (2008). Collaborative genome-wide association analysis supports a role for ANK3 and CACNA1C in bipolar disorder. Nature Genetics, 40(9), 1056-1058. DOI: $10.1038 / \mathrm{ng} .209$

Folstein, S. E., \& Rosen-Sheidley, B. (2001). Genetics of autism: complex aetiology for a heterogeneous disorder. Nature Reviews. Genetics, 2(12), 943-955. DOI: $10.1038 / 35103559$

Freimer, N. B., Reus, V. I., Escamilla, M. A., McInnes, L. A., Spesny, M., Leon, P., ... Sandkuijl, L. A. (1996). Genetic mapping using haplotype, association and linkage methods suggests a locus for severe bipolar disorder (BPI) at 18q22-q23. Nature Genetics, 12(4), 436-441. DOI: $10.1038 / \mathrm{ng} 0496-436$

Freimer, N. B., Reus, V. I., Escamilla, M., Spesny, M., Smith, L., Service, S., ... Sandkuijl, L. A. (1996). An approach to investigating linkage for bipolar disorder using large Costa Rican pedigrees. American Journal of Medical Genetics, 67(3), 254-263. DOI: 10.1002/ (SICI) 1096-8628(19960531)67:3<254::AIDAJMG3>3.0.CO;2-N

Garner, C., McInnes, L. A., Service, S. K., Spesny, M., Fournier, E., Leon, P., \& Freimer, N. B. (2001). Linkage analysis of a complex pedigree with severe bipolar disorder, using a Markov chain Monte Carlo method. American Journal of Human Genetics, 68(4), 1061-1064. DOI: 10.1086/319517

Giegling, I., Hosak, L., Mössner, R., Serretti, A., Bellivier, F., Claes, S., ... Rujescu, D. (2017). Genetics of schizophrenia: A consensus paper of the WFSBP Task Force on Genetics. The World Journal of Biological Psychiatry: The Official Journal of the World Federation of Societies of Biological Psychiatry, 18(7), 492-505. DOI: 10.1080/15622975.2016.1268715

Gladwin, T. E., Derks, E. M., Rietschel, M., Mattheisen, M., Breuer, R., Schulze, T. G., ... Ophoff, R. A. (2012). Segment-wise genome-wide association analysis identifies a candidate region associated with schizophrenia in three independent samples. PloS One, 7(6), e38828. DOI: 10.1371/journal. pone. 0038828

Glahn, D. C., Almasy, L., Barguil, M., Hare, E., Peralta, J. M., Kent, J. W., ... Escamilla, M. A. (2010). Neurocognitive endophenotypes for bipolar disorder identified in multiplex multigenerational families. Archives of General Psychiatry, 67(2), 168-177. DOI: 10.1001/archgenpsychiatry.2009.184 
Glahn, D. C., Knowles, E. E. M., McKay, D. R., Sprooten, E., Raventós, H., Blangero, J., ... Almasy, L. (2014). Arguments for the sake of endophenotypes: examining common misconceptions about the use of endophenotypes in psychiatric genetics. American Journal of Medical Genetics. Part B, Neuropsychiatric Genetics: The Official Publication of the International Society of Psychiatric Genetics, 165B(2), 122-130. DOI: 10.1002/ajmg.b.32221

Glahn, D. C., Nimgaonkar, V. L., Raventós, H., Contreras, J., McIntosh, A. M., Thomson, P. A., ... Blangero, J. (2018). Rediscovering the value of families for psychiatric genetics research. Molecular Psychiatry. DOI: $10.1038 / \mathrm{s} 41380-018-0073-\mathrm{x}$

Gonzalez, S., Camarillo, C., Rodriguez, M., Ramirez, M., Zavala, J., Armas, R., ... Escamilla, M. (2014). A genome-wide linkage scan of bipolar disorder in Latino families identifies susceptibility loci at $8 \mathrm{q} 24$ and 14q32. American Journal of Medical Genetics, 165(6), 479-491. DOI: 10.1002/ajmg.b.32251

Gonzalez, S., Xu, C., Ramirez, M. E., Zavala, J. M., Armas, R., Contreras, S. A., ... Escamilla, M. (2013a). Family-based association of an ANK3 haplotype with bipolar disorder in Latino populations. Translational Psychiatry, 3, e265. DOI: 10.1038/tp.2013.40

Gonzalez, S., Xu, C., Ramirez, M., Zavala, J., Armas, R., Contreras, S. A., ... Escamilla, M. (2013b). Suggestive evidence for association between L-type voltage-gated calcium channel (CACNA1C) gene haplotypes and bipolar disorder in Latinos: a familybased association study. Bipolar Disorders, 15(2), 206-214. DOI: 10.1111/bdi.12041

Gottesman, I. I., \& Gould, T. D. (2003). The Endophenotype Concept in Psychiatry: Etymology and Strategic Intentions. American Journal of Psychiatry, 160(4), 636-645. DOI: 10.1176/appi.ajp.160.4.636

Greenberg, D. A., Cayanis, E., Strug, L., Marathe, S., Durner, M., Pal, D. K., ... Kang, H. (2005). Malic Enzyme 2 May Underlie Susceptibility to Adolescent-Onset Idiopathic Generalized Epilepsy. The American Journal of Human Genetics, 76(1), 139146. DOI: $10.1086 / 426735$

Guella, I., Sequeira, A., Rollins, B., Morgan, L., Myers, R. M., Watson, S. J., ... Vawter, M. P. (2014). Evidence of allelic imbalance in the schizophrenia susceptibility gene ZNF804A in human dorsolateral prefrontal cortex. Schizophrenia Research, 152(1), 111-116. DOI: 10.1016/j.schres.2013.11.021

Gurling, H. M., Kalsi, G., Brynjolfson, J., Sigmundsson, T., Sherrington, R., Mankoo, B. S., ... Curtis, D. (2001). Genomewide genetic linkage analysis confirms the presence of susceptibility loci for schizophrenia, on chromosomes 1q32.2, 5q33.2, and 8p21-22 and provides support for linkage to schizophrenia, on chromosomes 11q23.3-24 and 20q12.1-11.23. American
Journal of Human Genetics, 68(3), 661-673. DOI: $10.1086 / 318788$

Hawton, K., Sutton, L., Haw, C., Sinclair, J., \& Harriss, L. (2005). Suicide and attempted suicide in bipolar disorder: a systematic review of risk factors. The Journal of Clinical Psychiatry, 66(6), 693-704.

Herzberg, I., Jasinska, A., García, J., Jawaheer, D., Service, S., Kremeyer, B., ... Ruiz-Linares, A. (2006). Convergent linkage evidence from two Latin-American population isolates supports the presence of a susceptibility locus for bipolar disorder in 5q3134. Human Molecular Genetics, 15(21), 3146-3153. DOI: $10.1093 / \mathrm{hmg} / \mathrm{dd} 1254$

Ho, B.-C., Wassink, T. H., Ziebell, S., \& Andreasen, N. C. (2011). Cannabinoid receptor 1 gene polymorphisms and marijuana misuse interactions on white matter and cognitive deficits in schizophrenia. Schizophrenia Research, 128(1-3), 66-75. DOI: 10.1016/j. schres.2011.02.021

Holliday, E. G., Mowry, B. J., \& Nyholt, D. R. (2008). A reanalysis of 409 European-Ancestry and African American schizophrenia pedigrees reveals significant linkage to $8 \mathrm{p} 23.3$ with evidence of locus heterogeneity. American Journal of Medical Genetics. Part B, Neuropsychiatric Genetics, 147B(7), 1080-1088. DOI: 10.1002/ajmg.b.30722

Hong, K. S., McInnes, L. A., Service, S. K., Song, T., Lucas, J., Silva, S., ... Freimer, N. B. (2004). Genetic mapping using haplotype and model-free linkage analysis supports previous evidence for a locus predisposing to severe bipolar disorder at 5q31-33. American Journal of Medical Genetics. Part B, Neuropsychiatric Genetics : The Official Publication of the International Society of Psychiatric Genetics, 125B(1), 83-86. DOI: 10.1002/ajmg.b.20091

Insel, T. R. (2010). Rethinking schizophrenia. Nature, 468(7321), 187-193. DOI: 10.1038/nature09552

Iyegbe, C., Campbell, D., Butler, A., Ajnakina, O., \& Sham, P. (2014). The emerging molecular architecture of schizophrenia, polygenic risk scores and the clinical implications for GxE research. Social Psychiatry and Psychiatric Epidemiology, 49(2), 169-182. DOI: 10.1007/s00127-014-0823-2

Jasinska, A., Service, S., Jawaheer, D., DeYoung, J., Levinson, M., Zhang, Z., ... Freimer, N. B. (2009). A narrow and highly significant linkage signal for severe bipolar disorder in the chromosome $5 \mathrm{q} 33$ region in Latin American pedigrees. American Journal of Medical Genetics, 150B(7), 998-1006. DOI: 10.1002/ ajmg.b.30956

Kalthoff, C., Groos, S., Kohl, R., Mahrhold, S., \& Ungewickell, E. J. (2002). Clint: A Novel Clathrinbinding ENTH-Domain Protein at the Golgi. Molecular Biology of the Cell, 13(11), 4060-4073. DOI: 10.1091/mbc.E02-03-0171 
Keen-Kim, D., Mathews, C. A., Reus, V. I., Lowe, T. L., Herrera, L. D., Budman, C. L., ... Freimer, N. B. (2006). Overrepresentation of rare variants in a specific ethnic group may confuse interpretation of association analyses. Human Molecular Genetics, 15(22), 3324-3328. DOI: $10.1093 / \mathrm{hmg} / \mathrm{ddl} 408$

Kukshal, P., Bhatia, T., Bhagwat, A. M., Gur, R. E., Gur, R. C., Deshpande, S. N., ... Thelma, B. K. (2013). Association study of neuregulin-1 gene polymorphisms in a North Indian schizophrenia sample. Schizophrenia Research, 144(1-3), 24-30. DOI: 10.1016/j. schres.2012.12.017

Kutejova, E., Briscoe, J., \& Kicheva, A. (2009). Temporal dynamics of patterning by morphogen gradients. Current Opinion in Genetics \& Development, 19(4), 315-322. DOI: 10.1016/j.gde.2009.05.004

Lambert, J.-C., \& Amouyel, P. (2011). Genetics of Alzheimer's disease: new evidences for an old hypothesis? Current Opinion in Genetics \& Development, 21(3), 295-301. DOI: 10.1016/j. gde.2011.02.002

Leckman, J. F., Grice, D. E., Boardman, J., Zhang, H., Vitale, A., Bondi, C., ... Pauls, D. L. (1997). Symptoms of obsessive-compulsive disorder. The American Journal of Psychiatry, 154(7), 911-917.

Lee, B. D., Walss-Bass, C., Thompson, P. M., Dassori, A., Montero, P. a, Medina, R., ... Escamilla, M. A. (2007). Malic enzyme 2 and susceptibility to psychosis and mania. Psychiatry Research, 150(1), 1-11. DOI: $10.1016 /$ j.psychres.2006.06.001

Lencz, T., Szeszko, P. R., DeRosse, P., Burdick, K. E., Bromet, E. J., Bilder, R. M., \& Malhotra, A. K. (2010). A schizophrenia risk gene, ZNF804A, influences neuroanatomical and neurocognitive phenotypes. $\mathrm{Neu}$ ropsychopharmacology, 35(11), 2284-2291. DOI: 10.1038/npp.2010.102

Leon, C. A., Schumacher, J., Kluck, N., Herold, C., Schulze, T. G., Propping, P., ... Jamra, R. A. (2011). Association study of the GRIA1 and CLINT1 (Epsin 4) genes in a German schizophrenia sample. Psychiatric Genetics, 21(2), 114. DOI: 10.1097/ YPG.0b013e328341a334

Lewis, C. M., Levinson, D. F., Wise, L. H., DeLisi, L. E., Straub, R. E., Hovatta, I., ... Helgason, T. (2003). Genome scan meta-analysis of schizophrenia and bipolar disorder, part II: Schizophrenia. American Journal of Human Genetics, 73(1), 34-48. DOI: $10.1086 / 376549$

Li, D., Collier, D. A., \& He, L. (2006). Meta-analysis shows strong positive association of the neuregulin 1 (NRG1) gene with schizophrenia. Human Molecular Genetics, 15(12), 1995-2002. DOI: 10.1093/hmg/ dd1122
Lindholm Carlström, E., Saetre, P., Rosengren, A., Thygesen, J. H., Djurovic, S., Melle, I., ... Jönsson, E. G. (2012). Association between a genetic variant in the serotonin transporter gene (SLC6A4) and suicidal behavior in patients with schizophrenia. Behavioral and Brain Functions: BBF, 8, 24. DOI: 10.1186/1744-9081-8-24

Liu, Y., Blackwood, D. H., Caesar, S., de Geus, E. J. C., Farmer, A., Ferreira, M. A. R., ... Sullivan, P. F. (2011). Meta-analysis of genome-wide association data of bipolar disorder and major depressive disorder. Molecular Psychiatry, 16(1), 2-4. DOI: 10.1038/ mp.2009.107

MacArthur, D. G., Balasubramanian, S., Frankish, A., Huang, N., Morris, J., Walter, K., ... Tyler-Smith, C. (2012). A systematic survey of loss-of-function variants in human protein-coding genes. Science, 335(6070), 823-828. DOI: 10.1126/science. 1215040

MacIntyre, D. J., Blackwood, D. H. R., Porteous, D. J., Pickard, B. S., \& Muir, W. J. (2003). Chromosomal abnormalities and mental illness. Molecular Psychiatry, 8(3), 275-287. DOI: 10.1038/sj.mp.4001232

Malhotra, A. K., Goldman, D., Mazzanti, C., Clifton, A., Breier, A., \& Pickar, D. (1998). A functional serotonin transporter (5-HTT) polymorphism is associated with psychosis in neuroleptic-free schizophrenics. Molecular Psychiatry, 3(4), 328-332.

Mamdani, M., McMichael, G. O., Gadepalli, V., Williamson, V., Parker, E. K., Haroutunian, V., \& Vladimirov, V. I. (2013). Differential regulation of schizophreniaassociated microRNA gene function by variable number tandem repeats (VNTR) polymorphism. Schizophrenia Research, 151(1-3), 284-286. DOI: 10.1016/j.schres.2013.10.024

Manolio, T. A. (2010). Genomewide association studies and assessment of the risk of disease. The New England Journal of Medicine, 363(2), 166-176. DOI: 10.1056/NEJMra0905980

Marballi, K., McCullumsmith, R. E., Yates, S., Escamilla, M. A., Leach, R. J., Raventos, H., \& Walss-Bass, C. (2014). Global signaling effects of a schizophreniaassociated missense mutation in neuregulin 1: an exploratory study using whole genome and novel kinome approaches. Journal of Neural Transmission, 479-490. DOI: 10.1007/s00702-013-1142-6

Marballi, K., Quinones, M. P., Jimenez, F., Escamilla, M. A., Raventós, H., Soto-Bernardini, M. C., ... Walss-Bass, C. (2010). In vivo and in vitro genetic evidence of involvement of neuregulin 1 in immune system dysregulation. Journal of Molecular Medicine, 88(11), 1133-1141. DOI: 10.1007/ s00109-010-0653-y

Marouli, E., Graff, M., Medina-Gomez, C., Lo, K. S., Wood, A. R., Kjaer, T. R., ... Lettre, G. (2017). Rare and low-frequency coding variants alter human adult 
height. Nature, 542(7640), 186-190. DOI: 10.1038/ nature21039

Marshall, C. R., Noor, A., Vincent, J. B., Lionel, A. C., Feuk, L., Skaug, J., ... Scherer, S. W. (2008). Structural variation of chromosomes in autism spectrum disorder. American Journal of Human Genetics, 82(2), 477-488. DOI: 10.1016/j.ajhg.2007.12.009

Martínez-Gras, I., Hoenicka, J., Ponce, G., RodríguezJiménez, R., Jiménez-Arriero, M. A., Pérez-Hernandez, E., ... Rubio, G. (2006). (AAT)n repeat in the cannabinoid receptor gene, CNR1: association with schizophrenia in a Spanish population. European Archives of Psychiatry and Clinical Neuroscience, 256(7), 437-441. DOI: 10.1007/s00406-006-0665-3

Mathews, C. A., \& Grados, M. A. (2011). Familiality of Tourette syndrome, obsessive-compulsive disorder, and attention-deficit/hyperactivity disorder: heritability analysis in a large sib-pair sample. Journal of the American Academy of Child and Adolescent Psychiatry, 50(1), 46-54. DOI: 10.1016/j.jaac.2010.10.004

Mathews, C, Amighetti, L. D. H., Lowe, T. L., Van De Wetering, B. J. M., Freimer, N. B., \& Reus, V. I. (2001). Cultural Influences on Diagnosis and Perception of Tourette Syndrome in Costa Rica. Journal of the American Academy of Child \& Adolescent Psychiatry, 40(4), 456-463. DOI: 10.1097/00004583-200104000-00015

Mathews, C., Jang, K. L., Herrera, L. D., Lowe, T. L., Budman, C. L., Erenberg, G., ... Reus, V. I. (2007). Tic symptom profiles in subjects with Tourette Syndrome from two genetically isolated populations. Biological Psychiatry, 61(3), 292-300. DOI: 10.1016/j. biopsych.2006.02.009

Mathews, C. A., Reus, V. I., Bejarano, J., Escamilla, M. A., Fournier, E., Herrera, L. D., ... Freimer, N. B. (2004). Genetic studies of neuropsychiatric disorders in Costa Rica: a model for the use of isolated populations. Psychiatric Genetics, 14(1), 13-23.

Maxwell, M. (1992) Family Interview for Genetic Studies (FIGS): A Manual for FIGS. Bethesda, MD: NIMH, Clinical Neurogenetics Branch.

Mayeux, R., \& Stern, Y. (2012). Epidemiology of Alzheimer disease. Cold Spring Harbor Perspectives in Medicine, 2(8), 1-18. DOI: 10.1101/cshperspect. a006239

McClellan, J. M., Susser, E., \& King, M.-C. (2007). Schizophrenia: a common disease caused by multiple rare alleles. The British Journal of Psychiatry: The Journal of Mental Science, 190, 194-199. DOI: 10.1192/ bjp.bp. 106.025585

McClellan, J., \& King, M.-C. (2010). Genetic heterogeneity in human disease. Cell, 141(2), 210-217. DOI: 10.1016/j.cell.2010.03.032
McGuffin, P., Rijsdijk, F., Andrew, M., Sham, P., Katz, R., \& Cardno, A. (2003). The heritability of bipolar affective disorder and the genetic relationship to unipolar depression. Archives of General Psychiatry, 60(5), 497-502. DOI: 10.1001/archpsyc.60.5.497

McInnes, L. a, Escamilla, M. a, Service, S. K., Reus, V. I., Leon, P., Silva, S., ... Freimer, N. B. (1996). A complete genome screen for genes predisposing to severe bipolar disorder in two Costa Rican pedigrees. Proceedings of the National Academy of Sciences of the United States of America, 93(23), 13060-13065.

McInnes, L., González, P. J., Manghi, E. R., Esquivel, M., Monge, S., Delgado, M. F., ... Castelle, K. (2005). A genetic study of autism in Costa Rica: multiple variables affecting IQ scores observed in a preliminary sample of autistic cases. BMC Psychiatry, 5, 15. DOI: 10.1186/1471-244X-5-15

McInnes, L. A., Nakamine, A., Pilorge, M., Brandt, T., Jiménez González, P., Fallas, M., ... Buxbaum, J. D. (2010). A large-scale survey of the novel $15 q 24$ microdeletion syndrome in autism spectrum disorders identifies an atypical deletion that narrows the critical region. Molecular Autism, 1(1), 5. DOI: $10.1186 / 2040-2392-1-5$

McInnes, L., Ouchanov, L., Nakamine, A., Jimenez, P., Esquivel, M., Fallas, M., ... Manghi, E. R. (2007). The NRG1 exon 11 missense variant is not associated with autism in the Central Valley of Costa Rica. BMC Psychiatry, 7, 21. DOI: 10.1186/1471-244X-7-21

McInnes, L. A., Service, S. K., Reus, V. I., Barnes, G., Charlat, O., Jawahar, S., ... Chen, H. (2001). Finescale mapping of a locus for severe bipolar mood disorder on chromosome 18p11.3 in the Costa Rican population. Proceedings of the National Academy of Sciences of the United States of America, 98(20), 11485-11490. DOI: 10.1073/pnas.191519098

Miguel, E. C., Leckman, J. F., Rauch, S., do RosarioCampos, M. C., Hounie, A. G., Mercadante, M. T., ... Pauls, D. L. (2005). Obsessive-compulsive disorder phenotypes: implications for genetic studies. Molecular Psychiatry, 10(3), 258-275. DOI: 10.1038/ sj.mp.4001617

Mirow, A. L., Kristbjanarson, H., Egeland, J. A., Shilling, P., Helgason, T., Gillin, J. C., ... Kelsoe, J. R. (1994). A linkage study of distal chromosome $5 \mathrm{q}$ and bipolar disorder. Biological Psychiatry, 36(4), 223-229.

Moon, E., Rollins, B., Mesén, A., Sequeira, A., Myers, R. M., Akil, H., ... Vawter, M. P. (2011). Lack of association to a NRG1 missense polymorphism in schizophrenia or bipolar disorder in a Costa Rican population. Schizophrenia Research, 131(1-3), 52-57. DOI: $10.1016 /$ j.schres.2011.06.024

Moreno-De-Luca, D., Mulle, J. G., Kaminsky, E. B., Sanders, S. J., Myers, S. M., Adam, M. P., ... Ledbetter, D. H. (2010). Deletion $17 \mathrm{q} 12$ is a recurrent copy 
number variant that confers high risk of autism and schizophrenia. American Journal of Human Genetics, 87(5), 618-630. DOI: 10.1016/j.ajhg.2010.10.004

Morera, B., \& Barrantes, R. (2004). Is the Central Valley of Costa Rica a genetic isolate? Revista De Biologia Tropical, 52(3), 629-644.

Morera, B., Barrantes, R., \& Marin-Rojas, R. (2003). Gene admixture in the Costa Rican population. Annals of Human Genetics, 67(Pt 1), 71-80.

Mowry, B. J., \& Gratten, J. (2013). The emerging spectrum of allelic variation in schizophrenia: current evidence and strategies for the identification and functional characterization of common and rare variants. Molecular Psychiatry, 18(1), 38-52. DOI: 10.1038/ mp.2012.34

Nakamine, A., Ouchanov, L., Jiménez, P., Manghi, E. R., Esquivel, M., Monge, S., ... McInnes, L. A. (2008). Duplication of $17(\mathrm{p} 11.2 \mathrm{p} 11.2)$ in a male child with autism and severe language delay. American Journal of Medical Genetics. Part A, 146A(5), 636-643. DOI: 10.1002/ajmg.a.31636

Ng, M. Y. M., Levinson, D. F., Faraone, S. V., Suarez, B. K., DeLisi, L. E., Arinami, T., ... Lewis, C. M (2009). Meta-analysis of 32 genome-wide linkage studies of schizophrenia. Molecular Psychiatry, 14(8), 774-785. DOI: $10.1038 / \mathrm{mp} .2008 .135$

Nurnberger, J. I., Blehar, M. C., Kaufmann, C. A., YorkCooler, C., Simpson, S. G., Harkavy-Friedman, J., ... Reich, T. (1994). Diagnostic interview for genetic studies. Rationale, unique features, and training. NIMH Genetics Initiative. Archives of General Psychiatry, 51(11), 849-859.

O’Donovan, M. C., Craddock, N., Norton, N., Williams, H., Peirce, T., Moskvina, V., ... Cloninger, C. R. (2008). Identification of loci associated with schizophrenia by genome-wide association and follow-up. Nature Genetics, 40(9), 1053-1055. DOI: 10.1038/ ng.201

Ophoff, R. A., Escamilla, M. A., Service, S. K., Spesny, M., Meshi, D. B., Poon, W., ... Freimer, N. B. (2002). Genomewide linkage disequilibrium mapping of severe bipolar disorder in a population isolate. American Journal of Human Genetics, 71(3), 565-574. DOI: $10.1086 / 342291$

Pacheco, A., Barguil, M., Contreras, J., Montero, P., Dassori, A., Escamilla, M. A., \& Raventós, H. (2010). Social and clinical comparison between schizophrenia and bipolar disorder type I with psychosis in Costa Rica. Social Psychiatry and Psychiatric Epidemiology, 45(6), 675-680. DOI: 10.1007/ s00127-009-0118-1

PAHO-WHO. (2013). WHO-AIMS: Report on Mental Health Systems in Latin America and the Caribbean. Washington, D.C.: Pan American Helth Organization
Park, N., Juo, S. H., Cheng, R., Liu, J., Loth, J. E., Lilliston, B., ... Baron, M. (2004). Linkage analysis of psychosis in bipolar pedigrees suggests novel putative loci for bipolar disorder and shared susceptibility with schizophrenia. Molecular Psychiatry, 9(12), 10911099. DOI: $10.1038 /$ sj.mp.4001541

Paunio, T., Ekelund, J., Varilo, T., Parker, A., Hovatta, I., Turunen, J. A., ... Peltonen, L. (2001). Genome-wide scan in a nationwide study sample of schizophrenia families in Finland reveals susceptibility loci on chromosomes 2q and 5q. Human Molecular Genetics, 10(26), 3037-3048.

Perkins, D. O., Jeffries, C. D., Jarskog, L. F., Thomson, M., Woods, K., Newman, M. A., \& Parker, J. S. (2007). microRNA expression in the prefrontal cortex of individuals with schizophrenia and schizoaffective disorder. Genome Biology, 8(2), R27. DOI: 10.1186/ gb-2007-8-2-r27

Petryshen, T. L., Middleton, F. A., Kirby, A., Aldinger, K. A., Purcell, S., Tahl, A. R., ... Sklar, P. (2005). Support for involvement of neuregulin 1 in schizophrenia pathophysiology. Molecular Psychiatry, 10(4), 366374, 328. DOI: 10.1038/sj.mp.4001608

Pimm, J., McQuillin, A., Thirumalai, S., Lawrence, J., Quested, D., Bass, N., ... Gurling, H. (2005). The Epsin 4 gene on chromosome 5q, which encodes the clathrin-associated protein enthoprotin, is involved in the genetic susceptibility to schizophrenia. American Journal of Human Genetics, 76(5), 902-907. DOI: $10.1086 / 430095$

Ramamoorthy, S., Bauman, A. L., Moore, K. R., Han, H., Yang-Feng, T., Chang, A. S., ... Blakely, R. D. (1993). Antidepressant- and cocaine-sensitive human serotonin transporter: molecular cloning, expression, and chromosomal localization. Proceedings of the National Academy of Sciences, 90(6), 2542-2546. DOI: 10.1073 pnas.90.6.2542

Raventós, H. \& Contreras, J. (2017). El diagnóstico en psiquiatría: una discusión teórica y práctica para el abordaje clínico. Acta Médica Costarricense, 59(4), 134-137.

Reitz, C., Brayne, C., \& Mayeux, R. (2011). Epidemiology of Alzheimer disease. Nature Reviews. Neurology, 7(3), 137-152. DOI: 10.1038/nrneurol.2011.2

Riley, B., Thiselton, D., Maher, B. S., Bigdeli, T., Wormley, B., McMichael, G. O., ... Kendler, K. S. (2010). Replication of association between schizophrenia and ZNF804A in the Irish Case-Control Study of Schizophrenia sample. Molecular Psychiatry, 15(1), 29-37. DOI: $10.1038 / \mathrm{mp} .2009 .109$

Risch, N., Spiker, D., Lotspeich, L., Nouri, N., Hinds, D., Hallmayer, J., ... Myers, R. M. (1999). A genomic screen of autism: evidence for a multilocus etiology. American Journal of Human Genetics, 65(2), 493507. DOI: $10.1086 / 302497$ 
Ronemus, M., Iossifov, I., Levy, D., \& Wigler, M. (2014). The role of de novo mutations in the genetics of autism spectrum disorders. Nature Reviews. Genetics, 15(2), 133-141. DOI: $10.1038 / \operatorname{nrg} 3585$

Ross, J., Badner, J., Garrido, H., Sheppard, B., Chavira, D. A., Grados, M., ... Mathews, C. A. (2011). Genomewide linkage analysis in Costa Rican families implicates chromosome $15 \mathrm{q} 14$ as a candidate region for OCD. Human Genetics, 130(6), 795-805. DOI: 10.1007/s00439-011-1033-6

Ruscio, A. M., Stein, D. J., Chiu, W. T., \& Kessler, R. C. (2010). The epidemiology of obsessive-compulsive disorder in the National Comorbidity Survey Replication. Molecular Psychiatry, 15(1), 53-63. DOI: 10.1038/mp.2008.94

Scharf, J. M., Yu, D., Mathews, C. A., Neale, B. M. Stewart, S. E., Fagerness, J. A., ... Pauls, D. L. (2013). Genome-wide association study of Tourette's syndrome. Molecular Psychiatry, 18(6), 721-728. DOI: $10.1038 / \mathrm{mp} .2012 .69$

Schizophrenia Psychiatric Genome-Wide Association Consortium. (2011). Genome-wide association study identifies five new schizophrenia loci. Nature Genetics, 43(10), 969-976. DOI: 10.1038/ng.940

Schizophrenia Working Group of the Psychiatric Genomics Consortium. (2014). Biological insights from 108 schizophrenia-associated genetic loci. Nature, 511(7510), 421-427. DOI: 10.1038/nature13595

Schulze, T. G., Detera-Wadleigh, S. D., Akula, N., Gupta, A., Kassem, L., Steele, J., ... McMahon, F. J. (2009). Two variants in Ankyrin 3 (ANK3) are independent genetic risk factors for bipolar disorder. Molecular Psychiatry, 14(5), 487-491. DOI: 10.1038/ mp.2008.134

Sebat, J., Levy, D. L., \& McCarthy, S. E. (2009). Rare structural variants in schizophrenia: one disorder, multiple mutations; one mutation, multiple disorders. Trends in Genetics: TIG, 25(12), 528-535. DOI: 10.1016/j.tig.2009.10.004

Segura-Wang, M., Raventós, H., Escamilla, M., \& Barrantes, R. (2010). Assessment of genetic ancestry and population substructure in Costa Rica by analysis of individuals with a familial history of mental disorder. Annals of Human Genetics, 74(6), 516-524. DOI: 10.1111/j.1469-1809.2010.00612.x

Segurado, R., Detera-Wadleigh, S. D., Levinson, D. F., Lewis, C. M., Gill, M., Nurnberger, J. I., ... Akarsu, N. (2003). Genome scan meta-analysis of schizophrenia and bipolar disorder, part III: Bipolar disorder. American Journal of Human Genetics, 73(1), 49-62. DOI: $10.1086 / 376547$

Seifuddin, F., Mahon, P. B., Judy, J., Pirooznia, M., Jancic, D., Taylor, J., ... Zandi, P. P. (2012). Meta-analysis of genetic association studies on bipolar disorder.
American Journal of Medical Genetics. Part B, Neuropsychiatric Genetics: The Official Publication of the International Society of Psychiatric Genetics, 159B(5), 508-518. DOI: 10.1002/ajmg.b.32057

Service, S., Molina, J., Deyoung, J., Jawaheer, D., Aldana, I., Vu, T., ... Freimer, N. (2006). Results of a SNP genome screen in a large Costa Rican pedigree segregating for severe bipolar disorder. American Journal of Medical Genetics, 141B(4), 367-373. DOI: 10.1002/ajmg.b.30323

Sheppard, B., Chavira, D., Azzam, A., Grados, M. A., Umaña, P., Garrido, H., \& Mathews, C. A. (2010). ADHD prevalence and association with hoarding behaviors in childhood-onset OCD. Depression and Anxiety, 27(7), 667-674. DOI: 10.1002/da.20691

Shink, E., Morissette, J., Villeneuve, A., Bordeleau, L., Rochette, D., Gagné, B., ... Barden, N. (2002). Support for the presence of bipolar disorder susceptibility loci on chromosome 5: heterogeneity in a homogeneous population in Quebec. Progress in Neuro-Psychopharmacology \& Biological Psychiatry, 26(7-8), 1273-1277.

Shugart, Y. Y., Samuels, J., Willour, V. L., Grados, M. A., Greenberg, B. D., Knowles, J. A., ... Nestadt, G. (2006). Genomewide linkage scan for obsessivecompulsive disorder: evidence for susceptibility loci on chromosomes 3q, 7p, 1q, 15q, and 6q. Molecular Psychiatry, 11(8), 763-770. DOI: 10.1038/ sj.mp.4001847

Sklar, P., Pato, M. T., Kirby, A., Petryshen, T. L., Medeiros, H., Carvalho, C., ... Pato, C. N. (2004). Genomewide scan in Portuguese Island families identifies $5 q 31-5 q 35$ as a susceptibility locus for schizophrenia and psychosis. Molecular Psychiatry, 9(2), 213-218. DOI: $10.1038 /$ sj.mp.4001418

Sklar, P., Ripke, S., Scott, L. J., Andreassen, O. A., Cichon, S., Craddock, N., ... Purcell, S. M. (2011). Largescale genome-wide association analysis of bipolar disorder identifies a new susceptibility locus near ODZ4. Nature Genetics, 43(10), 977-983. DOI: 10.1038/ng.943

Sklar, P., Smoller, J. W., Fan, J., Ferreira, M. A. R., Perlis, R. H., Chambert, K., ... Purcell, S. M. (2008). Whole-genome association study of bipolar disorder. Molecular Psychiatry, 13(6), 558-569. DOI: 10.1038/ sj.mp.4002151

Smoller, J. W., \& Finn, C. T. (2003). Family, twin, and adoption studies of bipolar disorder. American Journal of Medical Genetics, 123C(1), 48-58. DOI: 10.1002/ajmg.c.20013

Stefansson, H., Sarginson, J., Kong, A., Yates, P., Steinthorsdottir, V., Gudfinnsson, E., ... St Clair, D. (2003). Association of neuregulin 1 with schizophrenia confirmed in a Scottish population. American Journal of Human Genetics, 72(1), 83-87. 
Stefansson, H., Sigurdsson, E., Steinthorsdottir, V., Bjornsdottir, S., Sigmundsson, T., Ghosh, S., ... Stefansson, K. (2002). Neuregulin 1 and susceptibility to schizophrenia. American Journal of Human Genetics, 71(4), 877-892. DOI: 10.1086/342734

Steinberg, S., Mors, O., Børglum, A. D., Gustafsson, O., Werge, T., Mortensen, P. B., ... Stefansson, K. (2011). Expanding the range of ZNF804A variants conferring risk of psychosis. Molecular Psychiatry, 16(1), 59-66. DOI: 10.1038/mp.2009.149

Sullivan, P. F., Agrawal, A., Bulik, C., Andreassen, O. A., Borglum, A., Breen, G., ... Consortium, P. G. (2017). Psychiatric Genomics: An Update and an Agenda. BioRxiv, 115600. DOI: 10.1101/115600

Sullivan, P. F., Kendler, K. S., \& Neale, M. C. (2003). Schizophrenia as a complex trait: evidence from a meta-analysis of twin studies. Archives of General Psychiatry, 60(12), 1187-1192.

Tan, W., Wang, Y., Gold, B., Chen, J., Dean, M., Harrison, P. J., ... Law, A. J. (2007). Molecular Cloning of a Brain-specific, Developmentally Regulated Neuregulin 1 (NRG1) Isoform and Identification of a Functional Promoter Variant Associated with Schizophrenia. Journal of Biological Chemistry, 282(33), 2434324351. DOI: $10.1074 /$ jbc.M702953200

Tang, R. Q., Zhao, X. Z., Shi, Y. Y., Tang, W., Gu, N. F., Feng, G. Y., ... He, L. (2006). Family-based association study of Epsin 4 and Schizophrenia. Molecular Psychiatry, 11(4), 395-399. DOI: 10.1038/ sj.mp. 4001780

Torres, A. R., Prince, M. J., Bebbington, P. E., Bhugra, D., Brugha, T. S., Farrell, M., ... Singleton, N. (2006). Obsessive-compulsive disorder: prevalence, comorbidity, impact, and help-seeking in the British National Psychiatric Morbidity Survey of 2000. The American Journal of Psychiatry, 163(11), 1978-1985. DOI: 10.1176/appi.ajp.163.11.1978

Tsai, S. J., Wang, Y. C., \& Hong, C. J. (2000). Association study of a cannabinoid receptor gene (CNR1) polymorphism and schizophrenia. Psychiatric Genetics, 10(3), 149-151.

Ujike, H., Takaki, M., Nakata, K., Tanaka, Y., Takeda, T., Kodama, M., ... Kuroda, S. (2002). CNR1, central cannabinoid receptor gene, associated with susceptibility to hebephrenic schizophrenia. Molecular Psychiatry, 7(5), 515-518. DOI: 10.1038/ sj.mp.4001029

Valerio, D., Raventos, H., Schmeidler, J., Beeri, M. S., Villalobos, L. M., Bolaños-Palmieri, P., ... Silverman, J. M. (2014). Association of Apolipoprotein E-e4 and Dementia Declines with Age. The American Journal of Geriatric Psychiatry : Official Journal of the American Association for Geriatric Psychiatry, 22(10), 957-960. DOI: 10.1016/j.jagp.2014.03.008 van Grootheest, D. S., Cath, D. C., Beekman, A. T., \& Boomsma, D. I. (2005). Twin studies on obsessive-compulsive disorder: a review. Twin Research and Human Genetics, 8(5), 450-458. DOI: $10.1375 / 183242705774310060$

Veltman, J. A., \& Brunner, H. G. (2012). De novo mutations in human genetic disease. Nature Reviews. Genetics, 13(8), 565-575. DOI: 10.1038/nrg3241

Visscher, P. M., Wray, N. R., Zhang, Q., Sklar, P., McCarthy, M. I., Brown, M. A., \& Yang, J. (2017). 10 Years of GWAS Discovery: Biology, Function, and Translation. The American Journal of Human Genetics, 101(1), 5-22. DOI: 10.1016/j.ajhg.2017.06.005

Vos, T., Flaxman, A. D., Naghavi, M., Lozano, R., Michaud, C., Ezzati, M., ... Memish, Z. A. (2012). Years lived with disability (YLDs) for 1160 sequelae of 289 diseases and injuries 1990-2010: a systematic analysis for the Global Burden of Disease Study 2010. Lancet, 380(9859), 2163-2196. DOI: 10.1016/ S0140-6736(12)61729-2

Walss-Bass, C., Escamilla, M. A., Raventos, H., Montero, A. P., Armas, R., Dassori, A., ... Almasy, L. (2005). Evidence of genetic overlap of schizophrenia and bipolar disorder: linkage disequilibrium analysis of chromosome 18 in the Costa Rican population. American Journal of Medical Genetics. Part B, Neuropsychiatric Genetics, 139B(1), 54-60. DOI: 10.1002/ ajmg.b.30207

Walss-Bass, C., Liu, W., Lew, D., Villegas, R., Montero, P., Dassori, A., ... Raventos, H. (2006). A novel missense mutation in the transmembrane domain of neuregulin 1 is associated with schizophrenia. Biological Psychiatry, 60(6), 548-553. DOI: 10.1016/j. biopsych.2006.03.017

Walss-Bass, C., Montero, A., Armas, R., Dassori, A., Contreras, S., Liu, W., ... Escamilla, M. (2006). Linkage disequilibrium analyses in the Costa Rican population suggests discrete gene loci for schizophrenia at 8p23.1 and 8q13.3. Psychiatric Genetics, 16(4), 159168. DOI: 10.1097/01.ypg.0000218616.27515.67

Walss-Bass, C., Raventos, H., Montero, A. P., Armas, R., Dassori, A., Contreras, S., ... Escamilla, M. A. (2006). Association analyses of the neuregulin 1 gene with schizophrenia and manic psychosis in a Hispanic population. Acta Psychiatrica Scandinavica, 113(4), 314-321. DOI: 10.1111/j.1600-0447.2005.00631.x

Walss-Bass, C., Soto-Bernardini, M. C., Johnson-Pais, T., Leach, R. J., Ontiveros, A., Nicolini, H., ... Raventos, H. (2009). Methionine sulfoxide reductase: a novel schizophrenia candidate gene. American Journal of Medical Genetics. Part B, Neuropsychiatric Genetics, 150B(2), 219-225. DOI: 10.1002/ajmg.b.30791

Warburton, A., Breen, G., Rujescu, D., Bubb, V. J., \& Quinn, J. P. (2015). Characterization of a RESTRegulated Internal Promoter in the Schizophrenia 
Genome-Wide Associated Gene MIR137. Schizophrenia Bulletin, 41(3), 698-707. DOI: 10.1093/schbul/ sbu 117

Wesseling, C., Román, N., Quirós, I., Páez, L., García, V., Mora, A. M., ... Steenland, K. N. (2013). Parkinson's and Alzheimer's diseases in Costa Rica: a feasibility study toward a national screening program. Global Health Action, 6(3), 23061. DOI: 10.3402/gha. v6i0.23061

Williams, H. J., Norton, N., Dwyer, S., Moskvina, V., Nikolov, I., Carroll, L., ... O’Donovan, M. C. (2011). Fine mapping of ZNF804A and genome-wide significant evidence for its involvement in schizophrenia and bipolar disorder. Molecular Psychiatry, 16(4), 429441. DOI: $10.1038 / \mathrm{mp} .2010 .36$

Williams, N. M., Preece, A., Spurlock, G., Norton, N., Williams, H. J., Zammit, S., ... Owen, M. J. (2003). Support for genetic variation in neuregulin 1 and susceptibility to schizophrenia. Molecular Psychiatry, 8(5), 485-487. DOI: 10.1038/sj.mp.4001348

Wray, N. R., \& Gottesman, I. I. (2012). Using summary data from the danish national registers to estimate heritabilities for schizophrenia, bipolar disorder, and major depressive disorder. Frontiers in Genetics, 3(July), 118. DOI: 10.3389/fgene.2012.00118

Xu, W., Cohen-Woods, S., Chen, Q., Noor, A., Knight, J., Hosang, G., ... Vincent, J. B. (2014). Genome-wide association study of bipolar disorder in Canadian and UK populations corroborates disease loci including SYNE1 and CSMD1. BMC Medical Genetics, 15, 2. DOI: $10.1186 / 1471-2350-15-2$

Yu, D., Mathews, C. A., Scharf, J. M., Neale, B. M., Davis, L. K., Gamazon, E. R., ... Pauls, D. L. (2015). Crossdisorder genome-wide analyses suggest a complex genetic relationship between Tourette's syndrome and OCD. The American Journal of Psychiatry, 172(1), 82-93. DOI: 10.1176/appi.ajp.2014.13101306

Zhang, R., Valenzuela, R. K., Lu, S., Meng, L., Guo, T., Du, X., ... Ma, J. (2011). Is the conserved mammalian region of ZNF804A locus associated with schizophrenia? A population-based genetics analysis. Schizophrenia Research, 133(1-3), 159-164. DOI: 10.1016/j.schres.2011.09.012

Zhang, R., Yan, J.-D., Valenzuela, R. K., Lu, S.-M., Du, X.-Y., Zhong, B., ... Ma, J. (2012). Further evidence for the association of genetic variants of ZNF804A with schizophrenia and a meta-analysis for genome-wide significance variant rs1344706. Schizophrenia Research, 141(1), 40-47. DOI: 10.1016/j. schres.2012.07.013

Zhao, H., \& Nyholt, D. R. (2017). Gene-based analyses reveal novel genetic overlap and allelic heterogeneity across five major psychiatric disorders. Human Genetics, 136(2), 263-274. DOI: 10.1007/ s00439-016-1755-6 